\title{
Developmental sensitivity to cannabis use patterns and risk for Major Depressive Disorder in mid-life: Findings from 40 years of follow-up
}

\author{
*Tabea Schoeler, $\mathrm{PhD}^{3}$ \\ * Delphine Theobald, $\mathrm{PhD}^{2}$ \\ Jean-Baptiste Pingault, $\mathrm{PhD}^{3}$ \\ David $\mathrm{P}$ Farrington, $\mathrm{PhD}^{4}$ \\ Jeremy W Coid, FRC Psych ${ }^{5}$ \\ ** Sagnik Bhattacharyya, $\mathrm{PhD}^{1}$
}

${ }^{1}$ Institute of Psychiatry, Psychology \& Neuroscience, King's College London, UK.

${ }^{2}$ Department of Psychology, Kingston University, London, UK.

${ }^{3}$ Division of Psychology and Language Science, University College London, UK.

${ }^{4}$ Institute of Criminology, University of Cambridge, UK.

${ }^{5}$ Forensic Psychiatry Research Unit, Queens Mary's University, UK.

\section{Word count}

Abstract: 253

Text: 3959

* These authors contributed equally to this work.

**Corresponding author: Department of Psychosis Studies, Institute of Psychiatry, Psychology \& Neuroscience, King's College London, De Crespigny Park, London SE5 8AF, UK, Tel +44 207848 0955, Fax +44 207848 0976, Email: sagnik.2.bhattacharyya@kcl.ac.uk 


\begin{abstract}
Background

Evidence regarding the association between cannabis use and depression remain conflicting, especially as studies have not typically adopted a longitudinal design with a follow-up period that was long enough to adequately cover the risk period for onset of depression.
\end{abstract}

\title{
Method
}

Males from the Cambridge Study in Delinquent Development (CSDD) (N=285) were assessed 7 times from age 8 to 48 years to prospectively investigate the association between cannabis use and risk of Major Depressive Disorder (MDD). A combination of multiple analyses (logistic regression, Cox regression, fixed-effects analysis) was employed to explore the strength and direction of effect within different developmental stages.

\section{Results}

Multiple regression analyses revealed that early onset cannabis use (before age 18) but not late onset cannabis use (after age 27) was associated with a higher risk and shorter time until a subsequent MDD diagnosis. This effect was present in high-frequency ([Odds Ratio (OR) 8.83, 95\% Confidence Interval (CI) 1.29-70.79]; [Hazard Ratio (HR) 8.69, 95\%CI 2.07-36.52]) and low-frequency early-onset users ([OR2.41, 95\%CI 1.22-4.76]; [HR2.09, 95\%CI 1.16-3.74]). Effect of increased frequency of cannabis use on increased risk of subsequent MDD was observed only for use during adolescence (age 14-18) but not at later life stages, while controlling for observed and non-unobserved time-invariant factors. Conversely, MDD in adulthood (age 18-32) was linked to a reduction in subsequent cannabis use (age 32-48).

\section{Conclusions}

The present findings provide evidence implicating frequent cannabis use during adolescence as a risk factor for later life depression. Future studies should further examine causality of effects in larger samples. 


\section{INTRODUCTION}

Understanding the nature of the association between use of cannabis, the most widely used illicit drug worldwide (UNODC, 2015), and depressive disorders is important while considering health policies involving cannabis, because depressive disorders are the leading contributor to the global burden of disease attributable to mental and substance use disorders(Whiteford et al., 2013). While evidence is fairly consistent in support of cannabis use as a risk factor for the development of psychosis (Moore et al., 2007) and its relapse (Patel R et al., 2016, Schoeler et al., 2016b, Schoeler et al., 2016a), little consensus exists regarding its association with depressive disorders. This is particularly important in light of marked shifts in public attitudes to cannabis use and its legal standing in society in many countries (Benac and Caldwell, 2013). Although studies have reported feelings of depression, tiredness, lack of motivation, low energy and anxiety as the most commonly reported negative experiences in cannabis users (Reilly et al., 1998) and cross-sectional evidence suggests that higher levels of depressive symptoms may be associated with cannabis use (Schoeler et al., 2015), uncertainty remains regarding the precise nature of this relationship. For instance, integrating data from 4 different cohorts, Horwood et al. (2012) reported that two of the cohorts suggested that cannabis use leads to the development of depression, a third cohort suggested that depression leads to cannabis use, while the fourth one did not find that either of those relationships were significant when employing longitudinal modelling. Another integrative analysis (Silins et al., 2014) using participant-level data from 3 of these cohorts did not find any association with depression by age 25 , when they adjusted for potential confounders.

Other investigations that have tested the direction of this association (whether cannabis use leads to depression or vice versa) in the same sample yielded similarly contradictory results. Some 
suggest that cannabis use leads to depression (Hayatbakhsh et al., 2007), while others suggest that depression leads to increase(Feingold et al., 2015) or even decreases (Womack et al., 2016) in cannabis use. One study did not find any significant association (Repetto et al., 2008) and another one reported a bi-directional relationship between cannabis use and depression severity (Baggio et al., 2014). Similarly, results from investigations which tested a unidirectional hypothesis about the nature of this association in their sample are equivocal, with some suggesting that depression is a risk factor of subsequent cannabis use (Wittchen et al., 2007) while a larger number suggest that cannabis use is a risk factor for subsequent depression (Brook et al., 2002, Gage et al., 2015) (for a summary of observational studies see sTable 1., Supplementary Material).

A recent meta-analysis of longitudinal studies suggest moderate effects of cannabis use on the risk of development of depression (Lev-Ran et al., 2014), though confidence in these effects was offset by large variability across studies as well as methodological concerns. On balance, this suggests that the possibility of other unobserved sources of confounding, such as a common genetic liability influencing both cannabis use and depression cannot be ruled out (Lynskey et al., 2004). Studies that have explored dose-response relationships either did not find a significant effect of frequency of cannabis use on depression (Feingold et al., 2015, Repetto et al., 2008) or found evidence in support of a dose-response relationship (Brook et al., 2002, Gage et al., 2015). Other evidence reported that the ratio between delta-9-tetrahydrocannabinol (THC), the main psychoactive ingredient in the cannabis plant, and cannabidiol (CBD), the other main cannabinoid present in the extract of cannabis (i.e. the THC:CBD ratio) was not linked to depression scores in users (Schubart et al., 2011). This is supported by experimental studies that did not find that the administration of THC increased depressive symptoms in healthy subjects 
(Englund et al., 2015). Another important determinant of the effect of cannabis, i.e., use during a sensitive developmental period (Pope et al., 2003), was not considered by a majority of the studies. Among the few studies that included age of onset of cannabis use in their analyses, some found more adverse effects if started at a younger age (Hayatbakhsh et al., 2007, Horwood et al., 2012), while most were not indicative of moderating effects of age of onset of cannabis use on risk of depression (Horwood et al., 2012, Lev-Ran et al., 2014).

The main limitation of evidence to date is the lack of a life-span prospective design, combined with multi-wave assessments to follow up a cohort of individuals. Such an approach makes it possible to investigate the question of whether later life depression results from early onset cannabis use. This is particularly crucial as although cannabis use commonly starts in early or mid-adolescence (Wagner and Anthony, 2002), a diagnosis of depressive disorder typically manifests in middle or later life (Kessler et al., 2007). However, most studies to date have examined cohorts comprising only adolescents or young adults, with a maximum follow-up age of 34 years (cf. sTable 1., Supplementary Material), thus limiting their ability to detect the incidence of depression, a substantial proportion of which is likely to have onset beyond the follow-up period of these studies. This may largely explain the conflicting nature of association observed in previous studies. In the present study, we have addressed these limitations by employing a prospective, multi-wave, life-span cohort design (including more than 40 years of follow-up, to age 48). Specifically, we investigated the effects of cannabis use on the risk of developing a Major Depression Disorder (MDD) (First et al., 1998) by age 48, by:

(1) assessing the magnitude of the association between cannabis use and depression

(2) exploring whether the effects vary across different developmental stages 
(3) controlling for important observed confounders (other illicit drug use, comorbid mental disorder, employment status) and unobserved time-invariant sources of confounding in multiple fixed-effects analyses

(4) investigating the directionality of the association between cannabis use and depression

\section{METHODS}

\section{Study sample}

The Cambridge Study in Delinquent Development (CSDD) is a prospective longitudinal study of the development of offending and antisocial behaviour in a cohort of 411 boys born mostly in 1953 and living in an ethnically homogeneous, working-class urban area of London (Farrington et al., 2006). They represented the complete population of boys who were 8 years old at that time (1961/62) and were attending one of six primary schools in a deprived area in London. Multiple waves (T1- T7) of data collection, which included participant interviews [at ages 8 (T1), 10 (T2), 14 (T3), 16 (T4), 18 (T5), 32 (T6) and 48 (T7)] complemented information obtained from parents (annually) and teachers (bi-annually) between ages 8 and 15 years. 97\% of the sample was white and most were raised in two-parent working class households. A detailed description of the methods is included as supplementary material (cf. sAppendix 1., Supplementary Material). The study was approved by the Ethics Committee of the Institute of Psychiatry, Psychology \& Neuroscience.

\section{Measures}

Lifetime diagnosis of Major Depressive Disorder (MDD) and age of onset of MDD were assessed by a psychiatrist using the Structured Clinical Interview for DSM-IV (Diagnostic and Statistical Manual of Mental Disorders, 4th Edition) Axis I Disorders (SCID I) (First et al., 1998) 
as part of a psychiatric interview at T7. Frequency of cannabis use was assessed at T3, T5, T6 and T7. The cannabis use predictor was coded as a categorical variable that took into account age of first reported use [early-onset user (reported use at age 18 or before) vs. late-onset user (reported use subsequent to age 18)] and frequency of use [high-frequency user $(\geq 450$ times used across T3, T5, T6, T7) vs. low-frequency user $(<450$ times used $)]$. This cut-off was chosen to generate a "high-frequency" cannabis group based on cannabis use pattern reported by our sample, here defined as greater than twice the third quantile $\left(\mathrm{Q}_{3}\right)$ for number of times used $\left[\mathrm{Q}_{3}=\right.$ 200 times used in those who used it at least once in their lifetime]. Covariates included in the simple analysis were chosen based on previous research, including alcohol, cigarette and other illicit drug use, socioeconomic status, other psychiatric illness, behavioural and emotional problems in childhood, childhood anxiety and childhood conduct problems (for details see sAppendix 1, Supplementary Material). Those variables were included as binary variables, for which the higher category was indicative of disadvantage (e.g. low socioeconomic status, presence of childhood anxiety).

\section{Statistical methods}

Data was analysed using R3.1.3 comprising three main statistical approaches, which are described in more detail in the sAppendix 1 (Supplementary Material): First, simple logistic regression analysis to estimate the effect of cannabis use group on risk of subsequent diagnosis of MDD (presence vs. absence of MDD by age 48). Multiple regression analysis was carried out including those co-variates that were significantly $(\mathrm{p} \leq 0.05)$ associated with risk of MDD in chisquare tests (sTable 4., Supplementary Material). Second, simple and multiple Cox proportional hazard regression analysis was employed to test whether the time until diagnosis of MDD was 
significantly different between the different cannabis use groups. The proportional hazards assumption was checked, confirming that the assumption of proportionality was not violated for any of the variables included. Third, fixed-effects logistic regression models were fitted in order to extend the ordinary logistic regression by adjusting for time-invariant, non-observed, fixed factors that vary across individuals. In order to investigate the potential moderating effect of age of onset and frequency of use, we set up two developmental dependent models, including one that assessed the effect of changes in cannabis frequency on risk of development of MDD within the age range of 14-18 years, one within the age range of 18-32 years and one within the age range of 32-48 years. We ran a second set of fixed-effects models, in order to investigate any effect that may have occurred in the reverse direction. In the multiple regression models we included other illicit drug use, presence of other mental illness and employment status at age 48 as random-effects.

\section{RESULTS}

Out of the 411 boys assessed at baseline, complete multi-wave cannabis use and depression data (T1-T7) at follow up (age 48) was available for a total number of $\mathrm{N}=285$ (for follow-up flow chart see sFigure 1., Supplementary Material). Comparison of subjects with and those without complete data who were not included in the present analyses carried out, revealed that there were no significant differences between the two groups in early life demographic variables (substance use, antisocial behavior, conduct problems, social class, anxiety), later life outcomes (substance use and mental health outcomes (DSM-IV based) including depression, anxiety disorders, substance use disorders) and cannabis use across the life span (age 18, 32 and 48) (sTable 3., Supplementary Material). As shown in Table 1., cannabis use was common in this sample, 
comprising a proportion of $38.2 \%$ of subjects who used the substance at least once upto age 48 . The majority of subjects who had ever used cannabis started using the substance between ages 14 and $18(76 \%)$. Although most of the early-onset cannabis users used the substance only around this age $(51.8 \%)$ and did not continue subsequently, a quarter continued to use the substance subsequently (i.e. $24.1 \%$ reported use also at ages 32 and 48). A total of 58 subjects (20.4\%) received a diagnosis of MDD by the age of 48 , with an estimated mean age of onset of illness of 38.57 (SD 7.13). Significant ( $p \leq 0.05$ ) associations with risk of depression in exploratory analyses were found for cannabis use (ever used), other illicit drug use (ever used by age 32), other diagnosis of mental illness at age 48 and employment status at age 48 (cf. sTable 4., Supplementary Material).

TABLE 1. ABOUT HERE

Simple logistic regression analysis (Table 2.) revealed that those who had never used cannabis had the lowest risk for developing a depressive disorder, whilst the highest risk estimates were found for those who had an early onset of cannabis use (age 18 or before) and continued to use the substance throughout their life (cumulative use endorsed more than 450 times) $(\mathrm{OR}=$ $10.07[95 \%$ CI 2.33-51.61], $p=0.002$ ). The risk was reduced in magnitude but still significant for early-onset users who used cannabis less frequently throughout their life (OR=2.67[95\%CI 1.395.12], $p=0.003$ ). Alternative specifications of cut-off for defining low frequency and high frequency use for the early-onset and late-onset users did not change the direction of these results (data available on request). After controlling for potential confounders that were significantly associated with depression in simple analyses, including other illicit drug use, presence of other mental health illness and employment status, the effects of cannabis use remained significant for 
early-onset, high-frequency users ( $\mathrm{OR}=8.83[95 \% \mathrm{CI} 1.29-70.79], p=0.03$; Table 2.) as well as for early-onset-low-frequency users $(\mathrm{OR}=2.41[95 \% \mathrm{CI} 1.22-4.76], p=0.01)$. Including anxiety reported at age 14 and presence of a lifetime diagnosis of anxiety or other stress disorders in this model did not alter the results (cf. sTable 5. and sTable 6., Supplementary Material). In line with these results, Cox regression models (cf. Table 3.; Figure 1) showed that early-onset cannabis use was associated with a shorter time to onset of MDD for both low-frequency ([HR=2.09 [95\%CI 1.16-3.74], $p=0.01)$ and high-frequency cannabis users ([HR=8.69 [95\%CI 2.07-36.52], $p=0.003)$.

TABLE 2. ABOUT HERE

TABLE 3. ABOUT HERE

FIGURE 1 ABOUT HERE

As shown in Table 4., the results from the multiple, cross-lagged, fixed-effects models suggest that an increase in cannabis use frequency between ages 14-18 was associated with increased odds for the development of MDD in both early adulthood (age 18-32) by 1.08 [95\% CI 1.03$1.12]$ ( $p=0.0008)$ and subsequently (age 33-48) by $1.20[95 \%$ CI $1.10-1.31](p \leq 0.0001)$. Changes in cannabis use frequency at later life stages were not significantly associated with the development of subsequent depression. For instance, a change in cannabis frequency between 
age 18-32 was not a predictor for the development of MDD between age 33 to $48(1.05[95 \% \mathrm{CI}$ $0.99-1.11], p=0.10$ ). To explore the issue of reverse causation (i.e. whether cannabis use predicts outcome and vice versa, in the form of a two-way causal relationship), we also tested whether the development of MDD was associated with subsequent changes in the frequency of cannabis use. A diagnosis of MDD between age 18 to 32 was linked to a reduction in frequency of cannabis use between ages 32 and 48 by $0.72[95 \%$ CI $0.57-0.92]$ ( $p=0.009)$.

\section{TABLE 4. ABOUT HERE}

\section{DISCUSSION}

These results provide for the first time evidence suggesting early but not late onset cannabis use may be a risk factor for the subsequent development of major depressive disorder. We observed an effect that was not confounded by other observed and unobserved time-invariant risk factors such as shared genetic or environmental influences or factors that change over time such as the use of other substances or the presence of comorbid psychiatric illness. Adverse effects of cannabis use on the risk of development of MDD and on time until MDD diagnosis were present only in those who had used it at a younger age (before age 18) with the effects being greater in high-frequency user (OR 8.83 / HR 8.69, $p \leq 0.05)$ than in low-frequency users (OR 2.41 / HR 2.09, $p \leq 0.05$ ), while no significant adverse effects were present if cannabis use was initiated at an older age (age 27 onwards) (cf. Table 2. and Table 3.). Early-onset, high-frequency cannabis users experienced depression more than 5 years earlier compared to never users (41 vs. 46.65 years). This is consistent with the idea of developmental sensitivity to the adverse effects of cannabis (Pope et al., 2003), as well as with the results of our fixed-effects (FE) analysis. The 
risk of developing subsequent depression was predicted only by an increase in cannabis use during adolescence (between ages 14 and 18) but not early adulthood (between ages 18 and 32) or subsequently (use between ages 32 and 48). In addition, the results suggest that the effect of early-onset cannabis use cannot be explained by unobserved time-invariant sources of confounding such as shared genetic or stable environmental factors. This may also explain why previous longitudinal analyses of panel data in younger cohorts (up to the maximum age of 34, cf. sTable 1., Supplementary Material) have been inconclusive as to whether an increase of cannabis use leads to an increase in risk of depression over time(Horwood et al., 2012, Silins et al., 2014), even when dose-response patterns were tested(Repetto et al., 2008, Womack et al., 2016). Since cigarette use across the life-span was not significantly linked to the risk of MDD, our results were not confounded by smoking, consistent with previous studies(Hayatbakhsh et al., 2007). These findings are also consistent with evidence from animal research, in which longterm exposure of cannabinoids resulted in depression-like symptoms only in adolescent but not adult rats(Bambico et al., 2010). Interestingly, cross-lagged, fixed-effects analysis revealed that a diagnosis of MDD in adulthood (age 18-32) was predictive of reduction in cannabis use subsequently, which is consistent with evidence from a recent longitudinal study(Womack et al., 2016). While subsequent reduction in cannabis use may have been a result of depressed individuals receiving specific therapeutic input following contact with health services as a result of their depression, this was not specifically examined. While these results cannot completely rule out the possibility that depression may also lead to cannabis use (Horwood et al., 2012, Wittchen et al., 2007), e.g. as a form of self-medicating behaviour, this seems less likely. This is also in line with a previous meta-analysis reporting overall significant adverse effects of cannabis use on depression outcome (OR 1.17), with more pronounced effects being present in 
heavier users (OR 1.62) (Lev-Ran et al., 2014). As we cannot completely rule out the possibility that depression occurring early on in life led to subsequent initiation or continuation of cannabis us, these results should be treated with caution and future studies should investigate more thoroughly the bi-directional pathways between cannabis use and depression in order to definitively rule out the possibility of reverse causation, as in previous longitudinal studies examining causal nature of associations with cannabis use (Schoeler et al., 2016b, Schoeler et al., 2016c). Since we investigated different groups of cannabis-using subjects based on their usage pattern, future studies may also evaluate continuous measures of cannabis use, such as the number of joints smoked over specified life-periods. These results are to be considered against certain limitations of this study, such as comprising a select group of predominantly white males who grew up in a working class urban environment in the 1960s and 1970s. Therefore, the results may not generalize to the wider population and in particular to females, those from other ethnicities, individuals brought up in rural environments or children from different socioeconomic status. Future studies should therefore expand on this and include individuals from more heterogeneous backgrounds. Another limitation is the use of self-report measures of cannabis and other substance use leading to potential under-reporting and the inclusion of only modestly sized cannabis-user groups. The relatively modest size of our sample limits our ability to conclude with certainty that late-onset cannabis use does not increase the risk of depression over the long-term. However, sensitivity analysis carried out by combining the two late-onset groups in order to increase sample power did not change the conclusion $\left(\mathrm{OR}_{\text {late-onset }}=1.15\right.$, $p=0.81$ ). Although attrition in this sample was relatively low (Rocque et al., 2017), only the subsample for whom complete information on SCID I was available was included in our study. This reduced the sample size for the present analyses and may have induced bias in our 
estimates. However, non-assessed subjects were not strictly drop-outs and, hence, it is unlikely that this reflects a systematic bias linked to individual characteristics that would have confounded the association between cannabis use and risk of development of depression. This is also supported by the fixed effects analysis, which has the advantage of controlling for all unobserved time-invariant individual factors and confirmed the results from our multivariate models. Future studies should therefore include larger samples to assess the association between different trajectories of cannabis use and the risk of depression. Although we assessed a range of covariates at various time points, we cannot draw firm conclusions on whether or when other mediating or modifying factors impact on the relationship between cannabis use and risk of development. The lack of consideration of other potential unmeasured time-variant factors that cannot be accounted for in fixed-effects models (e.g. epigenetic phenomena) could have also affected the results. For instance, despite the use of longitudinal panel data, this design does not allow us to make definitive conclusions regarding causality since fixed-effects models can neither account for individual unmeasured factors that vary over time nor do they address sufficiently the possibility of reverse causality. However, as discussed in greater detail as part of supplementary material (Appendix 3.), these factors are unlikely to have affected the direction of results presented here. Regarding the assessment of cannabis use, it is worth noting at the outset that the present cohort study was initiated several decades ago, much before the population level effects of cannabis and other drug use began to be systematically measured. Hence, assessments of exposure were perhaps less optimal than if one were to initiate such a cohort now. Finally, it should be pointed out that MDD was only assessed at the last follow-up assessment (at age 48), which may have resulted in under-reporting. However, this is unlikely to have systematically affected either the cannabis unexposed or exposed groups or the early-onset or late-onset 
subgroups of cannabis users. Similarly, if self-reported cannabis use had been under-reported by users, which is usually not the case as data from studies that validated self-report information with biological tests suggest (Di Forti et al., 2012, Basurto et al., 2009, Denis et al., 2012), this is likely to have resulted in an underestimation of effect size. Hence, it is unlikely that underreporting as a result of recall bias would have affected the direction of relationship that we have observed. It should also be pointed out that we included only a relatively conservative outcome measure (presence of DSM-based diagnosis of MDD), for which reason we could not estimate the effect of cannabis use on more subtle depressive symptomatology across the life-span. Furthermore, we were not able to control for the effect of early life sub-clinical depressive or other affective symptomatology that predate the first onset of depression in our models. However, we attempted to address the possibility that early emotional disturbance or dysregulation may have in turn led to early onset cannabis use, we examined whether anxiety at age 14 was predictive of subsequent cannabis use, which was not the case when we tested the association for cannabis use reported at age $16(p=0.29)$, age $18(p=0.74)$, age $32(p=0.74)$ or age 48 ( $p=0.21)$. Hence, future studies should use multi-point assessments across the life-span to prospectively assess depressive outcomes both in terms of syndromal disorder as well as depressive symptoms as done in previous studies in young adults (Horwood et al., 2012) as well as include biological validation of the predictor of interest i.e., cannabis use. Future studies should also investigate other potential risk factors such as poor coping or emotional dysregulation that may influence or mediate the effects of cannabis use on risk of depression. Since the THC levels in the cannabis have increased in recent years (Mehmedic et al., 2010, ElSohly et al., 2016), with THC being only one of the more than 80 different cannabinoids 
identified to date (ElSohly and Gul, 2014), future investigations should also distinguish between different types of cannabis that differ in their potency and cannabinoid constituents.

In summary, we found that cannabis use, especially during a developmentally sensitive period of life is associated with subsequent risk of developing major depression after controlling for potential confounders, suggestive of a potential causal relationship, although future investigations on this topic are necessary in order to draw more definite conclusions. These results have important public health implications given that depressive disorders are one of the top ten causes of disability in the world (Whiteford et al., 2013).

\section{Funding}

The CSDD data collection was supported by the Home Office and the Department of Health. Sagnik Bhattacharyya was supported by the NIHR (NIHR Clinician Scientist Award; NIHR CS11-001) and the UK MRC (MR/J012149/1) and from the NIHR Mental Health Biomedical Research Centre at South London and Maudsley NHS Foundation Trust and King's College London.

\section{Contributors}

DPF provided the data. SB, DT and DF designed the study and supervised the analyses, TS and DT carried out the data analysis and wrote the first draft together with SB. J-BP and JWC provided data, reviewed the results and contributed to the final draft of the manuscript.

\section{Declaration of interest}

None. 


\section{REFERENCES}

Baggio S, N'goran AA, Deline S, Studer J, Dupuis M, Henchoz Y, Mohler-Kuo M, Daeppen J-B \& Gmel G (2014). Patterns of cannabis use and prospective associations with health issues among young males. Addiction 109, 937-945.

Bambico FR, Nguyen N-T, Katz N \& Gobbi G (2010). Chronic exposure to cannabinoids during adolescence but not during adulthood impairs emotional behaviour and monoaminergic neurotransmission. Neurobiology of disease 37, 641-655.

Basurto FZ, Montes JMG, Cubos PF, Santed FS, Ríos FL \& Moreno AM (2009). Validity of the self-report on drug use by university students: correspondence between self-reported use and use detected in urine. Psicothema 21, 213-219.

Benac N \& Caldwell A. (2013). Marijuana legalization gains support, confounding policymakers [Online]. Available: http://www.huffingtonpost.com/2013/06/29/marijuanalegalization_n_3521547.html [Accessed 28/01/2014].

Brook DW, Brook JS, Zhang C, Cohen P \& Whiteman M (2002). Drug use and the risk of major depressive disorder, alcohol dependence, and substance use disorders. Archives of general psychiatry 59, 1039-1044.

Denis C, Fatséas M, Beltran V, Bonnet C, Picard S, Combourieu I, Daulouède J-P \& Auriacombe M (2012). Validity of the self-reported drug use section of the Addiction Severity Index and associated factors used under naturalistic conditions. Substance use \& misuse 47, 356-363.

Di Forti M, Iyegbe C, Sallis H, Kolliakou A, Falcone MA, Paparelli A, Sirianni M, La Cascia C, Stilo SA \& Marques TR (2012). Confirmation that the AKT1 (rs2494732) genotype influences the risk of psychosis in cannabis users. Biological Psychiatry 72, 811-816.

Elsohly M \& Gul W (2014). Constituents of cannabis sativa. Handbook of Cannabis. Oxford University Press.

Elsohly MA, Mehmedic Z, Foster S, Gon C, Chandra S \& Church JC (2016). Changes in cannabis potency over the last two decades (1995-2014)-Analysis of current data in the united states. Biological psychiatry 79, 613-619.

Englund A, Atakan Z, Kralj A, Tunstall N, Murray R \& Morrison P (2015). The effect of five day dosing with THCV on THC-induced cognitive, psychological and physiological effects in healthy male human volunteers: A placebo-controlled, double-blind, crossover pilot trial. Journal of Psychopharmacology 30, 140-151.

Farrington DP, Coid JW, Harnett L, Jolliffe D, Soteriou N, Turner R \& West DJ (2006). Criminal careers up to age 50 and life success up to age 48: New findings from the Cambridge Study in Delinquent Development, London, Home Office Research, Development and Statistics Directorate London.

Feingold D, Weiser M, Rehm J \& Lev-Ran S (2015). The association between cannabis use and mood disorders: A longitudinal study. Journal of affective disorders 172, 211-218.

First MB, Spitzer RL, Gibbon M \& Williams JB (1998). Structured Clinical Interview for DSM-IV Axis I Disorders: Patient Edition (February 1996 Final), SCID-I/P, New York, Biometrics Research Department, New York State Psychiatric Institute.

Gage SH, Hickman M, Heron J, Munafò MR, Lewis G, Macleod J \& Zammit S (2015). Associations of Cannabis and Cigarette Use with Depression and Anxiety at Age 18: Findings from the Avon Longitudinal Study of Parents and Children. PloS one 10. 
Hayatbakhsh MR, Najman JM, Jamrozik K, Mamun AA, Alati R \& Bor W (2007).

Cannabis and anxiety and depression in young adults: a large prospective study. Journal of the American Academy of Child \& Adolescent Psychiatry 46, 408-417.

Horwood LJ, Fergusson DM, Coffey C, Patton GC, Tait R, Smart D, Letcher P, Silins E \& Hutchinson DM (2012). Cannabis and depression: an integrative data analysis of four Australasian cohorts. Drug and alcohol dependence 126, 369-378.

Kessler RC, Angermeyer M, Anthony JC, De Graaf R, Demyttenaere K, Gasquet I, De Girolamo G, Gluzman S, Gureje O \& Haro JM (2007). Lifetime prevalence and ageof-onset distributions of mental disorders in the World Health Organization's World Mental Health Survey Initiative. World Psychiatry 6, 168.

Lev-Ran S, Roerecke M, Le Foll B, George T, Mckenzie K \& Rehm J (2014). The association between cannabis use and depression: a systematic review and meta-analysis of longitudinal studies. Psychological Medicine 44, 797-810.

Lynskey MT, Glowinski AL, Todorov AA, Bucholz KK, Madden PaF, Nelson EC, Statham DJ, Martin NG \& Heath AC (2004). Major Depressive Disorder, Suicidal Ideation, and Suicide Attempt inTwins Discordant for Cannabis Dependence and Early-Onset Cannabis Use. Archives of general psychiatry 61, 1026-1032.

Mehmedic Z, Chandra S, Slade D, Denham H, Foster S, Patel AS, Ross SA, Khan IA \& Elsohly MA (2010). Potency trends of $\triangle 9$-THC and other cannabinoids in confiscated cannabis preparations from 1993 to 2008. Journal of forensic sciences 55, 1209-1217.

Moore THM, Zammit S, Lingford-Hughes A, Barnes TRE, Jones PB, Burke M \& Lewis G (2007). Cannabis use and risk of psychotic or affective mental health outcomes: a systematic review. Lancet 370, 319-328.

Patel R, Wilson R, Jackson R, Ball M, Shetty H, Broadbent M, Stewart R, Mcguire P \& S B (2016). Association of cannabis use with hospital admission and antipsychotic treatment failure in first episode psychosis: an observational study. BMJ Open 6, e009888.

Pope HG, Gruber AJ, Hudson JI, Cohane G, Huestis MA \& Yurgelun-Todd D (2003). Early-onset cannabis use and cognitive deficits: what is the nature of the association? Drug and alcohol dependence 69, 303-310.

Reilly D, Didcott P, Swift W \& Hall W (1998). Long-term cannabis use: characteristics of users in an Australian rural area. Addiction 93, 837-846.

Repetto PB, Zimmerman MA \& Caldwell CH (2008). A Longitudinal Study of Depressive Symptoms and Marijuana Use in a Sample of Inner-City African Americans. Journal of Research on Adolescence 18, 421-447.

Rocque M, Jennings WG, Piquero AR, Ozkan T \& Farrington DP (2017). The importance of school attendance: Findings from the Cambridge Study in Delinquent Development on the Life-Course Effects of Truancy. Crime \& Delinquency 63, 592-612.

Schoeler T, Kambeitz J, Behlke I, Murray R \& Bhattacharyya S (2015). The effects of cannabis on memory function in users with and without a psychotic disorder: findings from a combined meta-analysis. Psychological Medicine, 1-12.

Schoeler T, Petros N, Di Forti M, Klamerus E, Foglia E, Ajnakina O, Gayer-Anderson C, Colizzi M, Quattrone D, Behlke I, Shetty S, Mcguire P, David A, Murray R \& Bhattacharyya $\mathbf{S}$ (2016a). Effects of continuation, frequency and type of cannabis use on relapse in the first two years following onset of psychosis - an observational study. Lancet Psychiatry 3, 947-953. 
Schoeler T, Petros N, Di Forti M, Pingault J, Klamerus E, Foglia E, Small A, Murray R \& Bhattacharyya S (2016b). Examining the association between continued cannabis use and risk of relapse in first episode psychosis: a quasi-experimental investigation within an observational study. JAMA Psychiatry 73, 1173-1179.

Schoeler T, Theobald D, Pingault J, Farrington D, Jennings W, Piquero A, Coid J \& Bhattacharyya S (2016c). Continuity of cannabis use and violent offending over the life course. Psychological Medicine, 1.

Schubart CD, Sommer IEC, Van Gastel WA, Goetgebuer RL, Kahn RS \& Boks MPM (2011). Cannabis with high cannabidiol content is associated with fewer psychotic experiences. Schizophrenia research 130, 216-221.

Silins E, Horwood LJ, Patton GC, Fergusson DM, Olsson CA, Hutchinson DM, Spry E, Toumbourou JW, Degenhardt L, Swift W, Coffey C, Tait RJ, Letcher P, Copeland J \& Mattick RP (2014). Young adult sequelae of adolescent cannabis use: an integrative analysis. Lancet Psychiatry 1, 286-293.

Unodc (2015). World Drug Report 2015. The United Nations Office on Drugs and Crime.

Wagner FA \& Anthony JC (2002). From first drug use to drug dependence: developmental periods of risk for dependence upon marijuana, cocaine, and alcohol.

Neuropsychopharmacology $\mathbf{2 6}$.

Whiteford HA, Degenhardt L, Rehm J, Baxter AJ, Ferrari AJ, Erskine HE, Charlson FJ, Norman RE, Flaxman AD \& Johns N (2013). Global burden of disease attributable to mental and substance use disorders: findings from the Global Burden of Disease Study 2010. Lancet 382, 1575-1586.

Wittchen H-U, Fröhlich C, Behrendt S, Günther A, Rehm J, Zimmermann P, Lieb R \& Perkonigg A (2007). Cannabis use and cannabis use disorders and their relationship to mental disorders: a 10-year prospective-longitudinal community study in adolescents. Drug and alcohol dependence $\mathbf{8 8}$, S60-S70.

Womack SR, Shaw DS, Weaver CM \& Forbes EE (2016). Bidirectional associations between cannabis use and depressive symptoms from adolescence through early adulthood among at-risk young men. Journal of studies on alcohol and drugs 77, 287-297. 
Figure(s)

Click here to download Figure(s) Figure1.pdf $\underline{\underline{*}}$

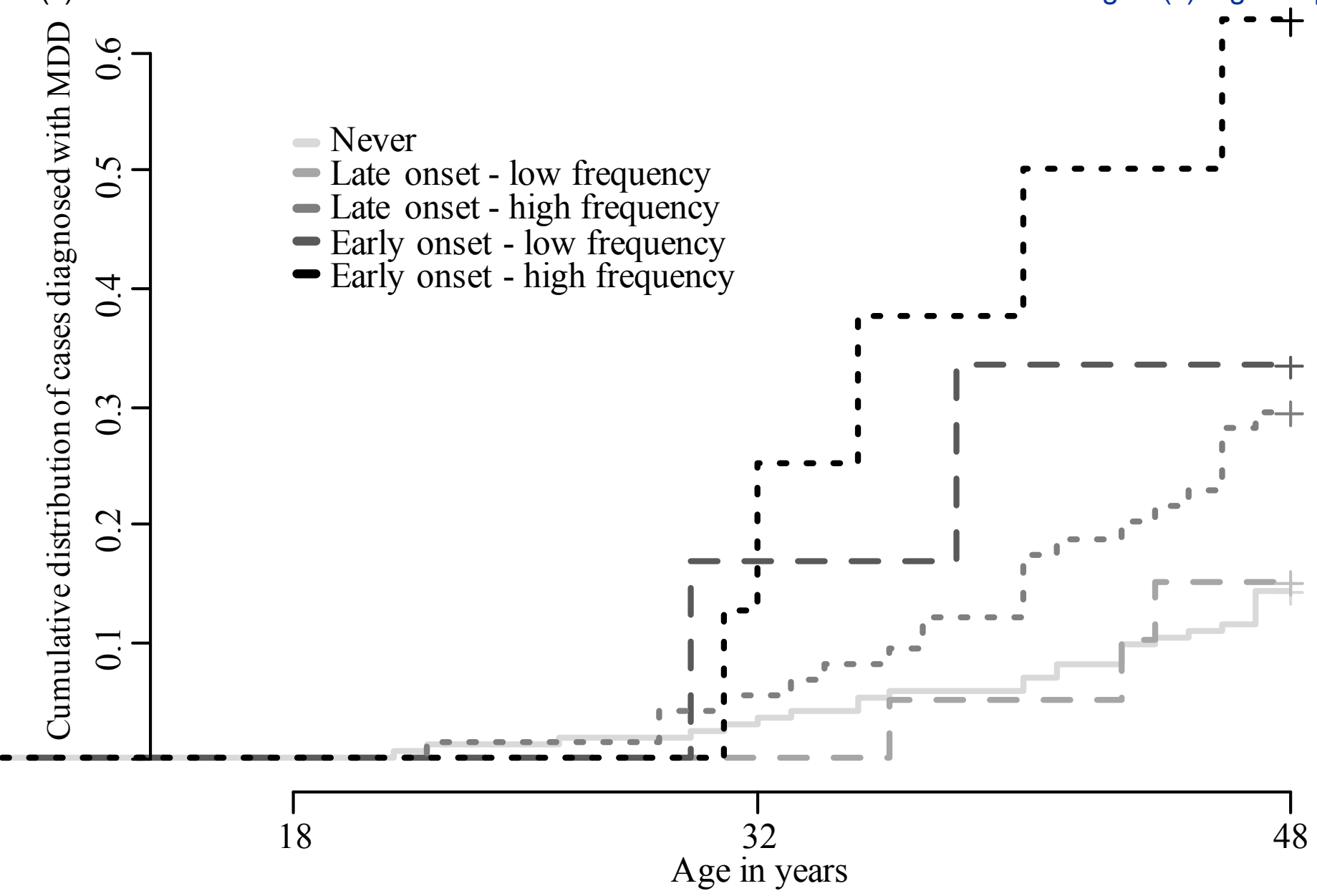


Table 2. Cannabis profiles and risk of subsequent MDD: Logistic regression analyses*

\begin{tabular}{lccc}
\hline \hline Simple logistic regression (N=284) & OR & $\mathbf{9 5 \%}$ CI & $\boldsymbol{p}$ \\
\hline Cannabis late onset - low frequency & 0.71 & $0.11-2.69$ & 0.66 \\
Cannabis late onset - high frequency & 3.02 & $0.40-16.34$ & 0.22 \\
Cannabis early onset - low frequency & 2.67 & $1.39-5.12$ & $\mathbf{0 . 0 0 3}$ \\
Cannabis early onset - high frequency & 10.07 & $2.33-51.61$ & $\mathbf{0 . 0 0 2}$ \\
\hline Multiple logistic regression (N=284) & $\mathbf{O R}$ & $\mathbf{9 5 \%}$ CI & $\boldsymbol{p}$ \\
\hline Cannabis late onset - low frequency & 0.68 & $0.10-2.65$ & 0.63 \\
Cannabis late onset - high frequency & 2.23 & $0.26-14.94$ & 0.42 \\
Cannabis early onset - low frequency & 2.41 & $1.22-4.76$ & $\mathbf{0 . 0 1}$ \\
Cannabis early onset - high frequency & 8.83 & $1.29-70.79$ & $\mathbf{0 . 0 3}$ \\
Other mental illness (yes) & 2.18 & $1.15-4.14$ & $\mathbf{0 . 0 2}$ \\
Other illicit drug use (yes) & 1.10 & $0.28-3.75$ & 0.88 \\
Employment status (unemployed) & 2.34 & $1.19-4.53$ & $\mathbf{0 . 0 1}$
\end{tabular}

Note. Reference group $=$ never cannabis users; Early onset $=$ Cannabis use at age 18 or before; High frequency $=\geq 450$ cumulative number of times used across time points (ages $18,32,48$ )

$*_{n}=1$ cases excluded since MDD was diagnosed prior to cannabis use 
Table 3. Cannabis profiles and time until subsequent MDD: Hazard ratios (HR)*

\begin{tabular}{lccc}
\hline Simple Cox Regression (N=284) & HR & $\mathbf{9 5 \%}$ CI & $\boldsymbol{p}$ \\
\hline Cannabis late onset - low frequency & 1.05 & $0.32-3.49$ & 0.93 \\
Cannabis late onset - high frequency & 2.90 & $0.69-12.25$ & 0.15 \\
Cannabis early onset - low frequency & 2.26 & $1.27-4.01$ & $\mathbf{0 . 0 0 5}$ \\
Cannabis early onset - high frequency & 6.65 & $2.54-17.41$ & $\mathbf{0 . 0 0 0 1}$ \\
\hline Multiple Cox Regression (N=284) & HR & $\mathbf{9 5 \%}$ CI & $\boldsymbol{p}$ \\
\hline Cannabis late onset - low frequency & 1.06 & $0.32-3.54$ & 0.92 \\
Cannabis late onset - high frequency & 2.77 & $0.61-12.51$ & 0.19 \\
Cannabis early onset - low frequency & 2.09 & $1.16-3.74$ & $\mathbf{0 . 0 1}$ \\
Cannabis early onset - high frequency & 8.69 & $2.07-36.52$ & $\mathbf{0 . 0 0 3}$ \\
Other mental illness (yes) & 1.78 & $1.05-3.03$ & $\mathbf{0 . 0 3}$ \\
Other illicit drug use (yes) & 0.73 & $0.25-2.15$ & 0.56 \\
Employment status (unemployed) & 1.97 & $1.14-3.41$ & $\mathbf{0 . 0 2}$
\end{tabular}

Note. Reference group = never cannabis users; Early onset = Cannabis use at age 18 or before; High frequency $=\geq 450$ cumulative number of times used across time points (ages $18,32,48$ )

$*_{\mathrm{n}}=1$ cases excluded since MDD was diagnosed prior to cannabis use 
Table 4. Fixed effects regression analysis

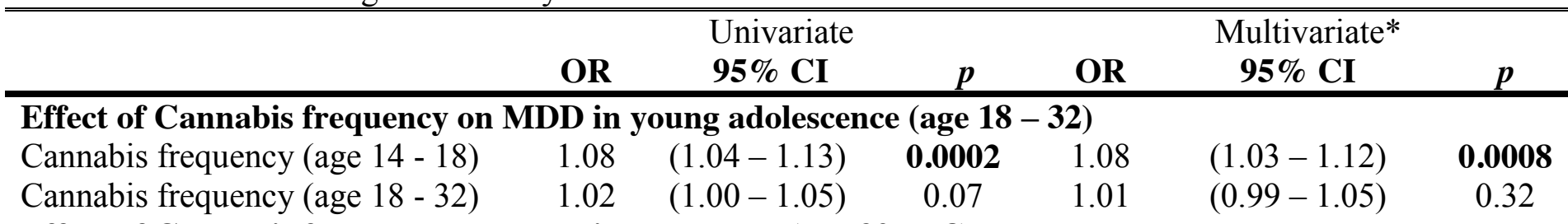

Effect of Cannabis frequency on MDD in adulthood (age 32 - 48)

$\begin{array}{lllllll}\text { Cannabis frequency }(\text { age } 14-18) & 1.22 & (1.12-1.33) & <\mathbf{0 . 0 0 0 1} & 1.20 & (1.10-1.31) & <0.0001\end{array}$

$\begin{array}{lllllll}\text { Cannabis frequency }(\text { age } 18-32) & 1.07 & (1.02-1.13) & \mathbf{0 . 0 0 7} & 1.05 & (0.99-1.11) & 0.10\end{array}$

$\begin{array}{lllllll}\text { Cannabis frequency (age } 32-48) & 1.04 & (0.99-1.09) & 0.17 & 1.01 & (0.95-1.07) & 0.76\end{array}$

Est. $\quad 95 \% \mathrm{CI} \quad$ Est. $\quad 95 \% \mathrm{CI}$

\begin{tabular}{lcccccc}
\hline Effect of MDD on cannabis frequency in adulthood (age 32 $-\mathbf{4 8})$ & & & \\
MDD (age 18 - 32) & 0.77 & $(0.59-0.99)$ & $\mathbf{0 . 0 5}$ & 0.72 & $(0.57-0.92)$ & $\mathbf{0 . 0 0 9}$ \\
MDD (age 32 - 48) & 1.07 & $(0.94-1.21)$ & 0.33 & 1.02 & $(0.90-1.15)$ & 0.77
\end{tabular}

Note. Increase in frequency = increase in one unit [(0) non-user; (1) low frequency user; (2) high frequency user]

*Controlled for random effects, including (1) other psychiatric illness and (2) other illicit drug use, (3) employment status at age 48 
Table 1. Cannabis and depression trajectories $(\mathrm{N}=285)$

\begin{tabular}{llc}
\hline \hline Age of onset MDD & Mean in years (SD) & $38.57(7.13)$ \\
Diagnosis of MDD & Ever diagnosed (yes) (n) & $20.4 \%(58)$ \\
& Before $18(n)$ & $0 \%(0)$ \\
& Between $18-32(n)$ & $22.4 \%(13)$ \\
Cannabis use trajectory & Between 33-48 $(n)$ & $77.6 \%(45)$ \\
& Ever used (yes) & $38.2 \%(109)$ \\
& Onset up to $14(n)$ & $0 \%(0)$ \\
& Onset between $15-18(n)$ & $76.1 \%(83)$ \\
& Onset between $27-32(n)$ & $13.8 \%(15)$ \\
Cannabis use pattern & Onset between 43-48 $(n)$ & $10.1 \%(11)$ \\
& Never used (n) & $61.8 \%(176)$ \\
& Late onset - low frequency (n) & $0.08 \%(22)$ \\
& Late onset - high frequency (n) & $0.01 \%(4)$ \\
& Early onset - low frequency $(\mathrm{n})$ & $0.27 \%(78)$ \\
& Early onset - high frequency $(\mathrm{n})$ & $0.02 \%(5)$ \\
Cannabis-Depression Trajectory & Cannabis $\rightarrow$ MDD & $32(11.3 \%)$ \\
& Cannabis $\rightarrow$ no MDD & $75(26.3 \%)$ \\
& Never cannabis, no MDD & $152(53.3 \%)$ \\
& Never cannabis $\rightarrow$ MDD & $25(8.8 \%)$ \\
& MDD $\rightarrow$ Cannabis & $1(0.4 \%)$ \\
\hline
\end{tabular}

Note. MDD = Diagnosis of Major Depression Disorder based on Structured Clinical Interview for DSM-IV Axis I Disorders (SCID-I) 


\title{
SUPPLEMENTARY MATERIAL
}

\section{Developmental sensitivity to cannabis use patterns and risk for Major Depressive Disorder in mid-life: Findings from 40 years of follow-up}

\author{
*Tabea Schoeler, $\mathrm{PhD}^{3}$ \\ *Delphine Theobald, $\mathrm{PhD}^{2}$ \\ Jean-Baptiste Pingault, $\mathrm{PhD}^{3}$ \\ David $\mathrm{P}$ Farrington, $\mathrm{PhD}^{4}$ \\ Jeremy W Coid, FRC Psych ${ }^{5}$ \\ ** Sagnik Bhattacharyya, $\mathrm{PhD}^{1}$
}

\begin{abstract}
${ }^{1}$ Institute of Psychiatry, Psychology \& Neuroscience, King's College London, UK. ${ }^{2}$ Department of Psychology, Kingston University, London, UK.

${ }^{3}$ Division of Psychology and Language Science, University College London, UK.

${ }^{4}$ Institute of Criminology, University of Cambridge, UK.

${ }^{5}$ Forensic Psychiatry Research Unit, Queens Mary's University, UK.

* These authors contributed equally to this work.

**Corresponding author: Department of Psychosis Studies, Institute of Psychiatry, Psychology \& Neuroscience, King's College London, De Crespigny Park, London SE5 8AF, UK, Tel +44 207848 0955, Fax +44 207848 0976, Email:

sagnik.2.bhattacharyya@kcl.ac.uk
\end{abstract}

Includes

sAppendix 1. Methods

sAppendix 2. Supplementary results

sAppendix 3. Supplementary discussion

sReferences

sTable 1. Summary of observational studies looking at the association between cannabis and depression

sTable 2. Prevalence of diagnosis of other mental illness

sTable 3. Differences in demographics and outcome in later life and between completers and drop outs

sTable 4. Childhood and life factors associated with risk of MDD by age 48

sTable 5. Anxiety and risk of subsequent MDD: Logistic regression analysis

sTable 6. Anxiety/stress disorder and risk of MDD: Logistic regression analysis

sTable 7. Sensitivity analysis: Cannabis profiles and risk of subsequent MDD (Logistic regression analyses)

sFigure 1. Follow up flow chart 


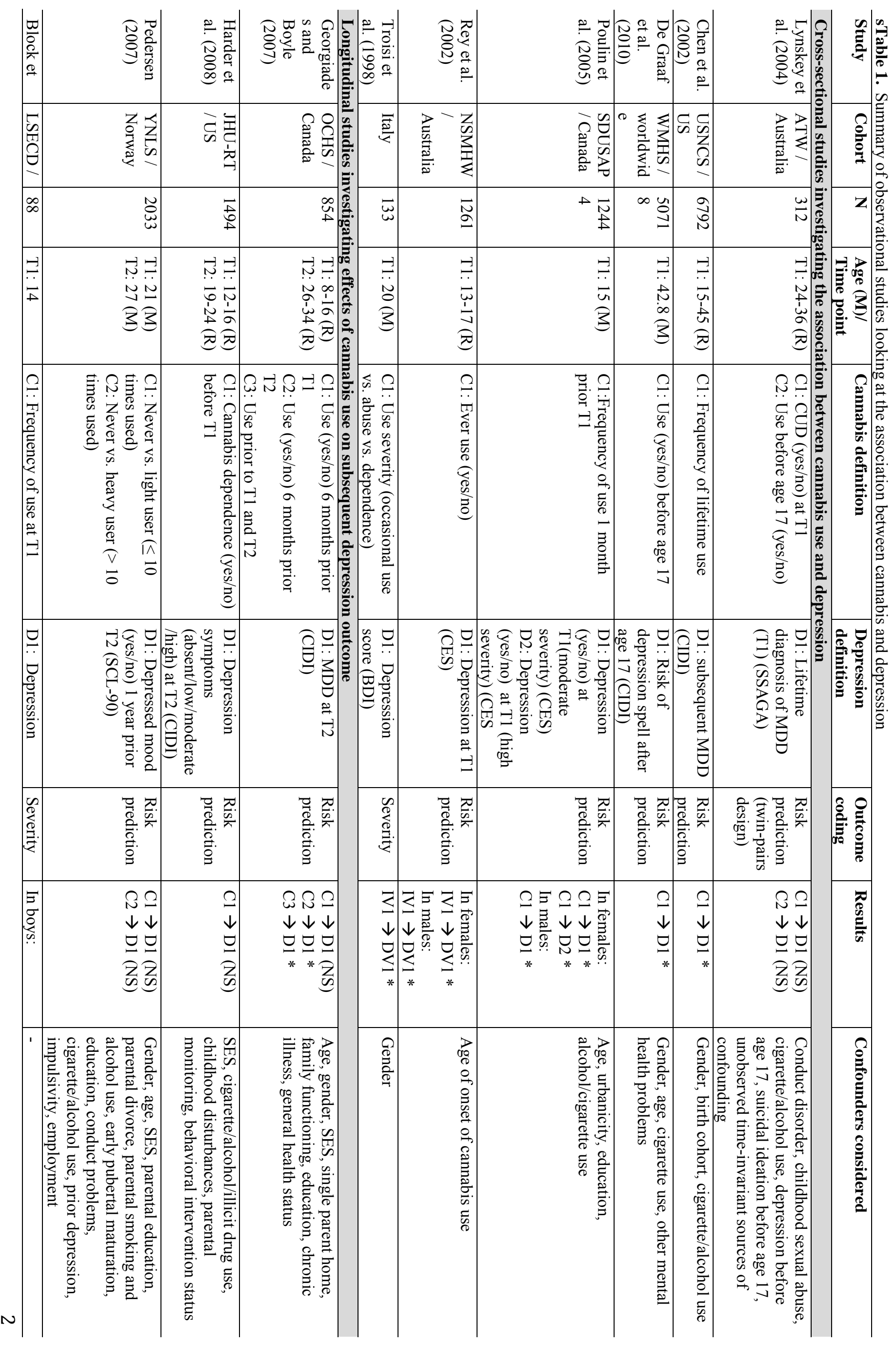




\begin{tabular}{|c|c|c|c|c|c|c|c|c|c|}
\hline & 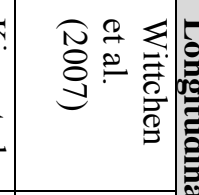 & $\begin{array}{ll}\stackrel{\varpi}{0} & 0 \\
\hat{N} & 0 \\
0 & 0 \\
0 & 9\end{array}$ & 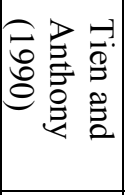 & 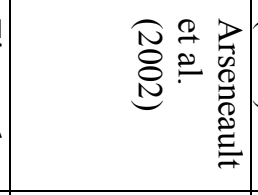 & 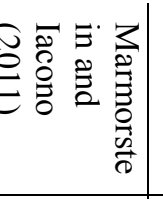 & 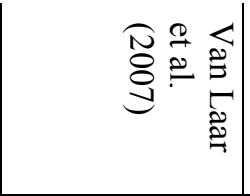 & 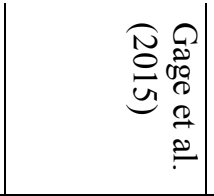 & 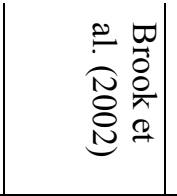 & $\begin{array}{l}\stackrel{2}{\mathscr{G}} \\
\stackrel{6}{\mathscr{b}}\end{array}$ \\
\hline & 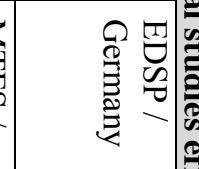 & 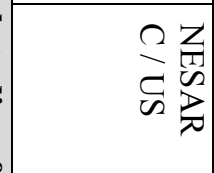 & $\stackrel{\widetilde{T}}{\Theta}$ & 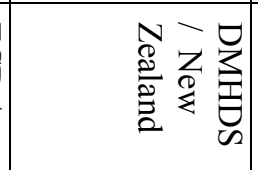 & 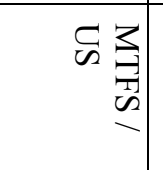 & 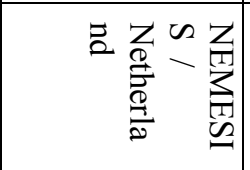 & 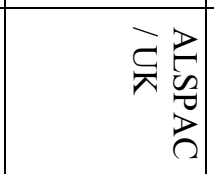 & $\begin{array}{l}\frac{\Omega}{2} \\
\frac{\Omega}{n}\end{array}$ & $\stackrel{I}{\mathscr{S}}$ \\
\hline$\stackrel{\omega}{\perp}$ & 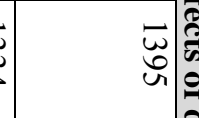 & 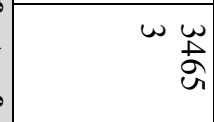 & $\begin{array}{l}\vec{t} \\
\stackrel{0}{\circ}\end{array}$ & ปు & $\begin{array}{l}\bar{N} \\
\stackrel{N}{N}\end{array}$ & $\begin{array}{l}w \\
\infty \\
\infty \\
0\end{array}$ & $\begin{array}{l}\vec{u} \\
\text { ○̆ }\end{array}$ & $\vec{w}$ & \\
\hline & 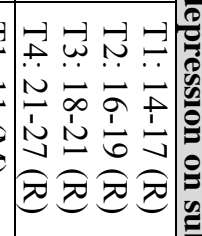 & 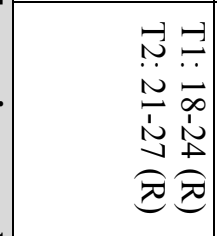 & 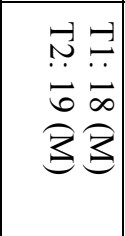 & 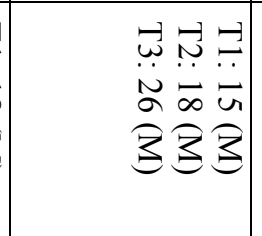 & 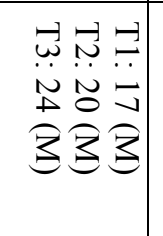 & 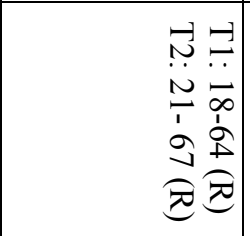 & 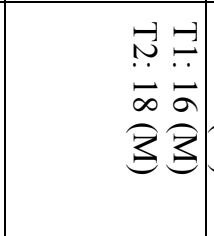 & 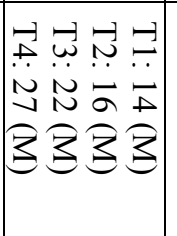 & $\begin{array}{l}\stackrel{+}{\oplus} \\
\stackrel{\infty}{ }\end{array}$ \\
\hline 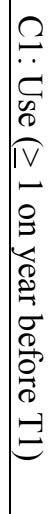 & 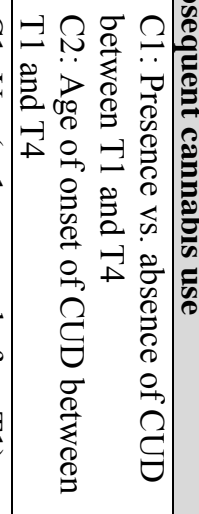 & 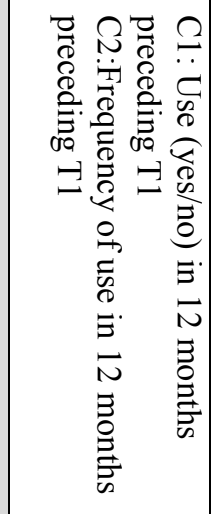 & 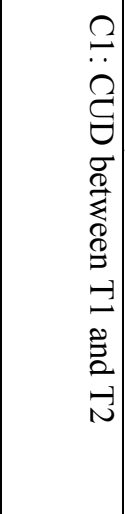 & 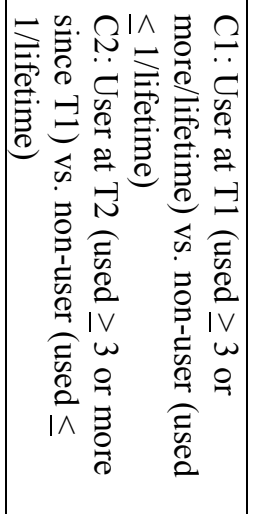 & 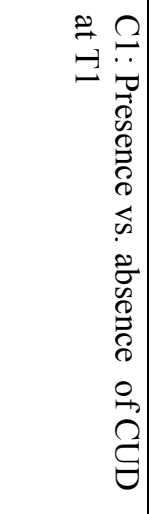 & 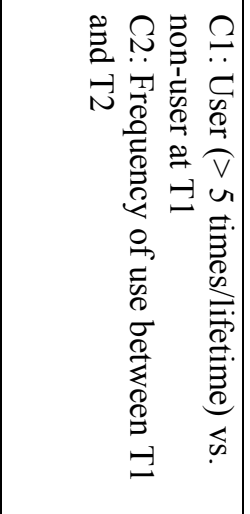 & 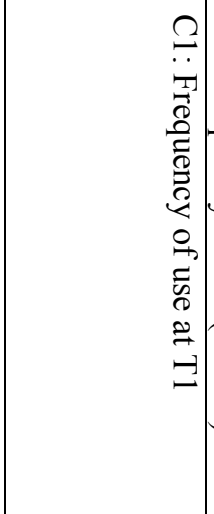 & 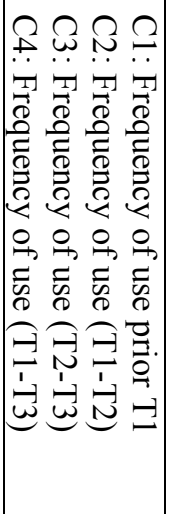 & \\
\hline $\begin{array}{l}\exists \\
\cong \\
\exists\end{array}$ & 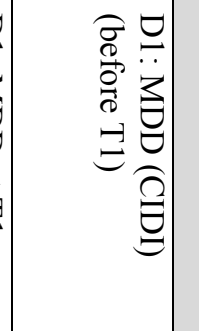 & 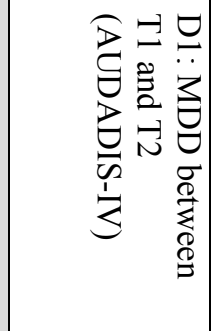 & 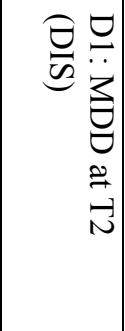 & 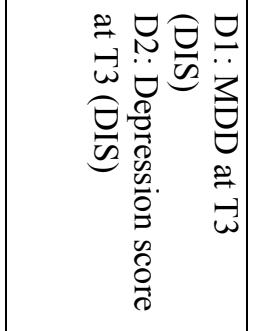 & 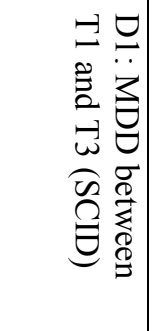 & 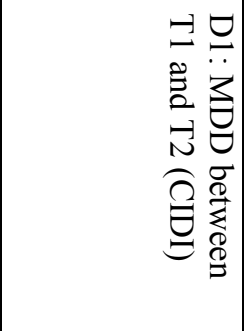 & 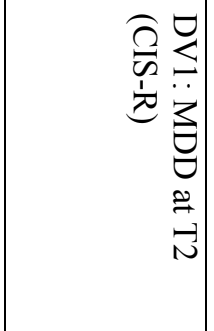 & 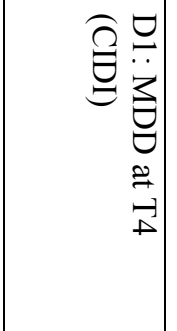 & 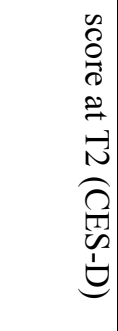 \\
\hline 总. & 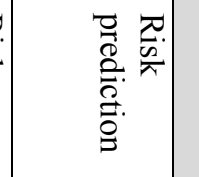 & 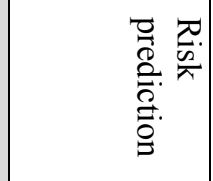 & 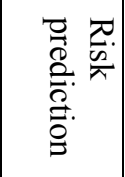 & 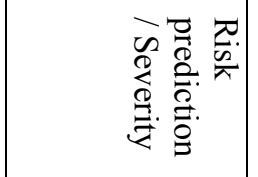 & 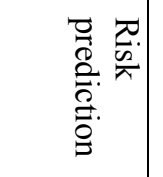 & 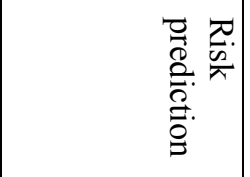 & 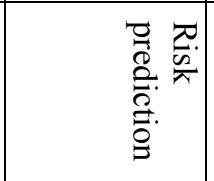 & 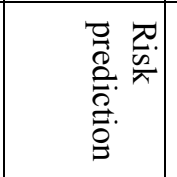 & \\
\hline 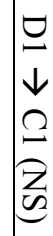 & $\begin{array}{ll}\Xi & \Xi \\
\downarrow & \downarrow \\
\sim & \Omega \\
* & *\end{array}$ & 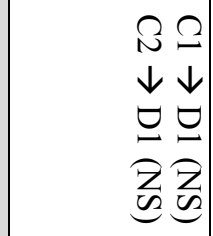 & $\begin{array}{l}\Omega \\
\downarrow \\
\stackrel{\Xi}{\sigma} \\
*\end{array}$ & 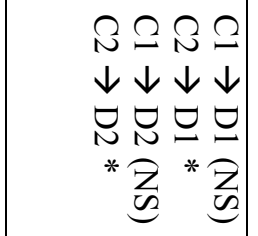 & $\begin{array}{l}\Omega \\
\downarrow \\
\Xi \\
* \\
*\end{array}$ & 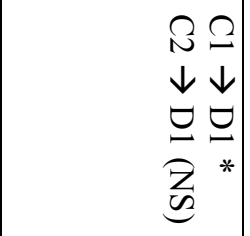 & $\begin{array}{l}\Omega \\
\downarrow \\
\bullet \\
*\end{array}$ & 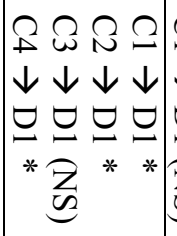 & 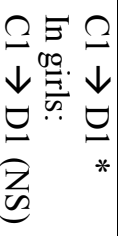 \\
\hline \& & 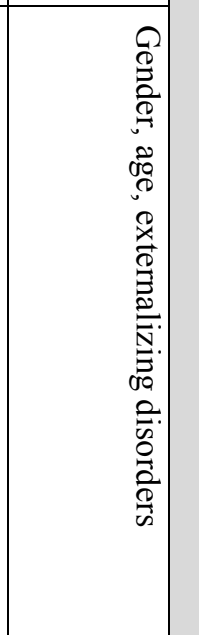 & 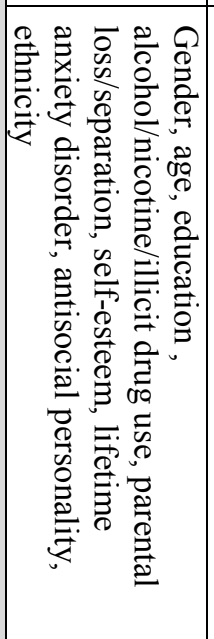 & 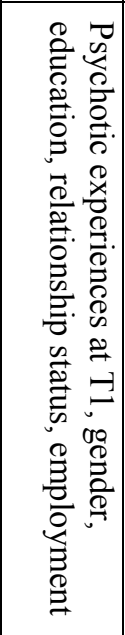 & 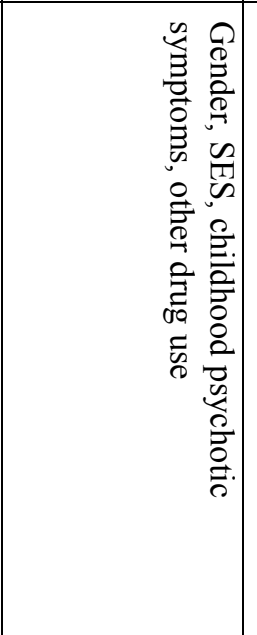 & & 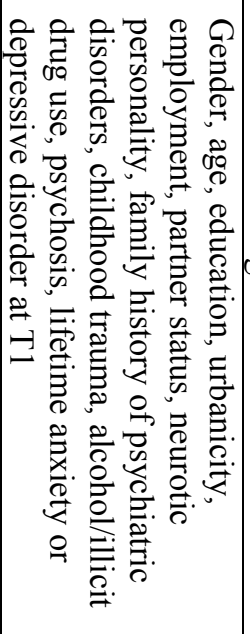 & 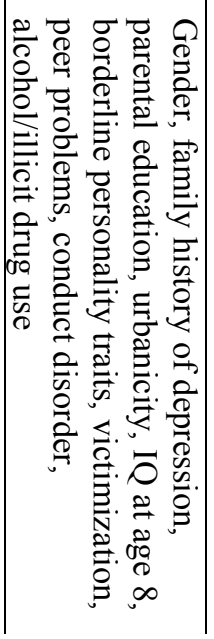 & 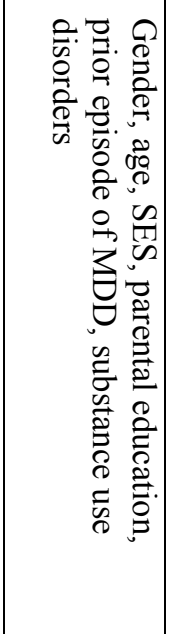 & \\
\hline
\end{tabular}




\begin{tabular}{|c|c|c|c|c|c|c|c|c|}
\hline 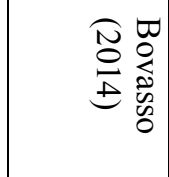 & 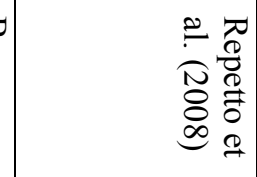 & 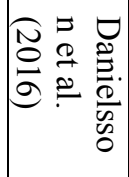 & 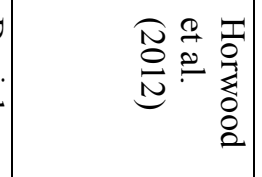 & 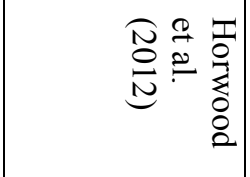 & 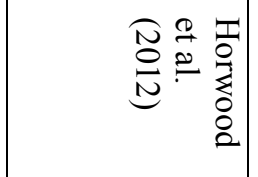 & 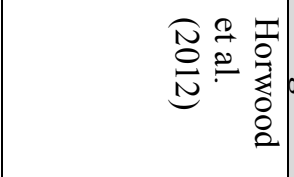 & 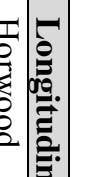 & $\begin{array}{l}\widehat{N} \\
\vdots \\
\triangleq\end{array}$ \\
\hline 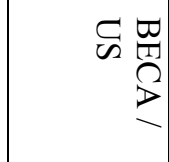 & I & 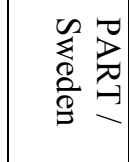 & 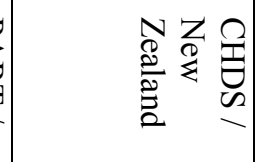 & 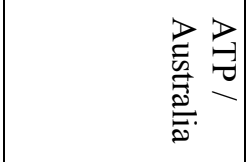 & 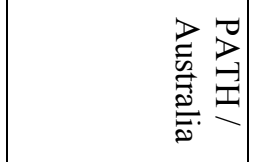 & 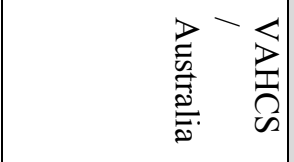 & 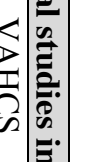 & I \\
\hline $\begin{array}{l}\infty \\
\stackrel{+}{6}\end{array}$ & N & $\begin{array}{l}\infty \\
0 \\
\infty \\
\infty\end{array}$ & $\begin{array}{l}\bar{N} \\
\hat{\sim}\end{array}$ & $\begin{array}{l}N \\
+ \\
+\end{array}$ & \begin{tabular}{l} 
\\
\multirow{+}{*}{} \\
+
\end{tabular} & $\begin{array}{l}\text { No } \\
\text { 心 } \\
\text { No }\end{array}$ & 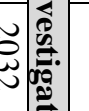 & \\
\hline 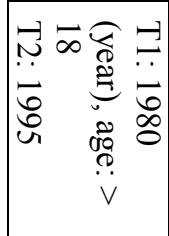 & 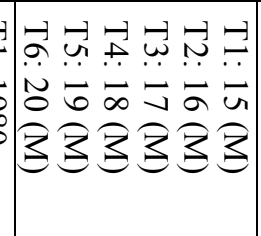 & 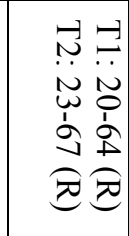 & 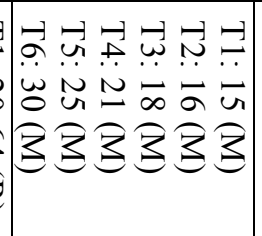 & 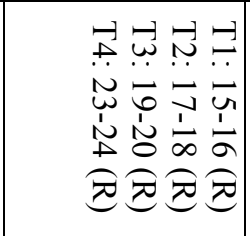 & 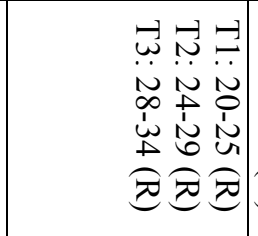 & 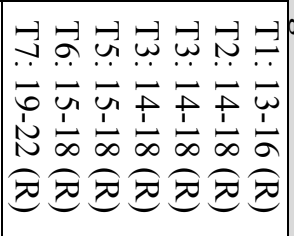 & 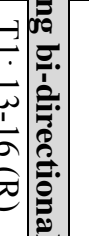 & $\begin{array}{l}\overrightarrow{1} \\
\stackrel{+}{+} \\
\stackrel{+}{Z} \\
3\end{array}$ \\
\hline 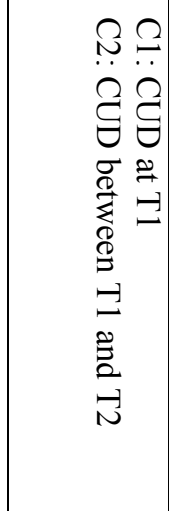 & 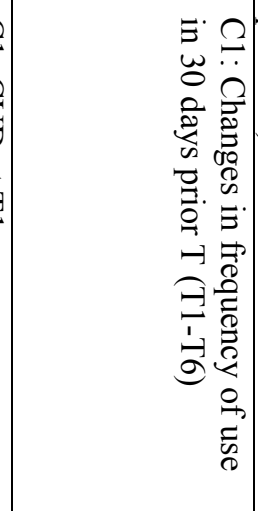 & 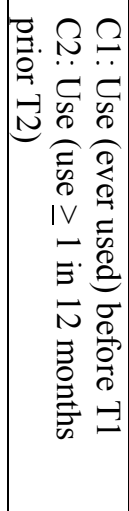 & 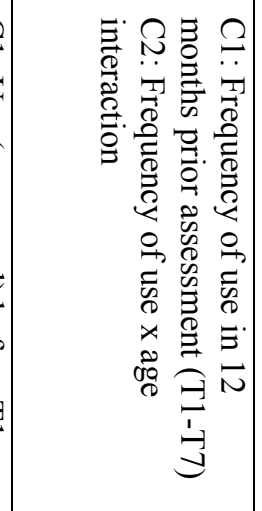 & 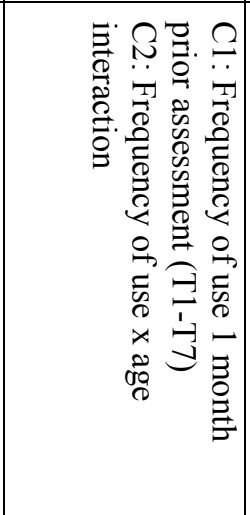 & 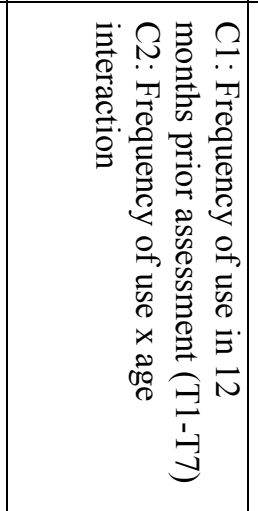 & 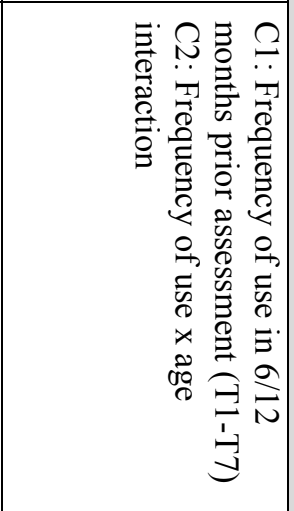 & 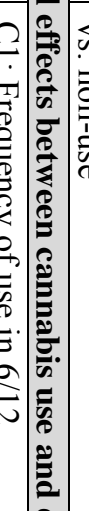 & 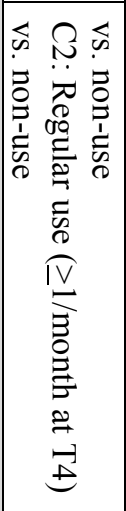 \\
\hline 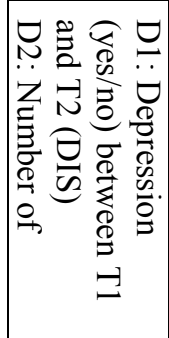 & 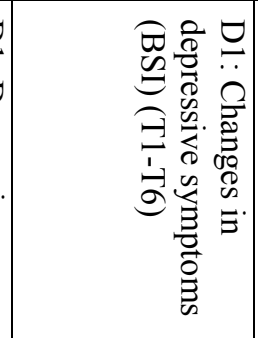 & 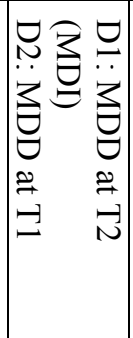 & 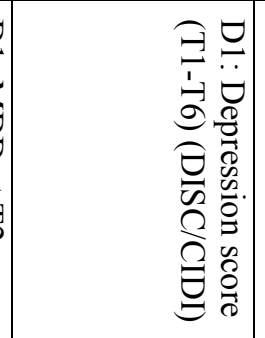 & 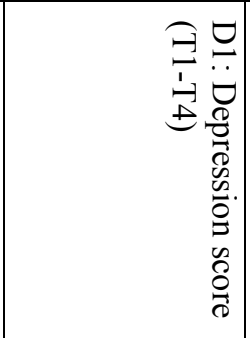 & 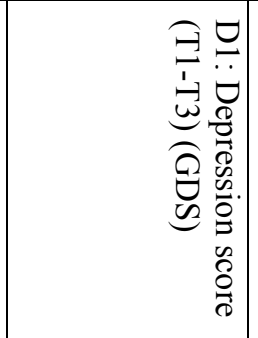 & 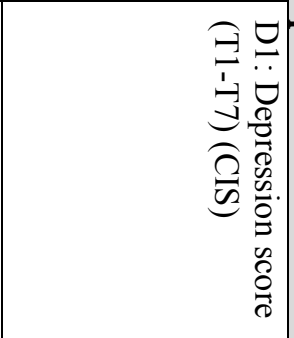 & 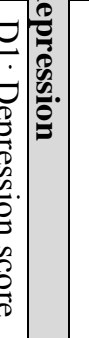 & $\stackrel{\theta}{\hat{\theta}}$ \\
\hline 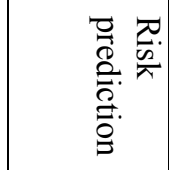 & 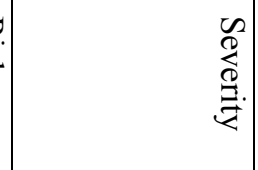 & 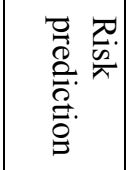 & 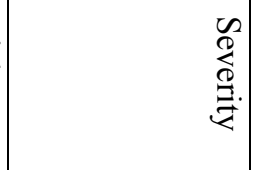 & 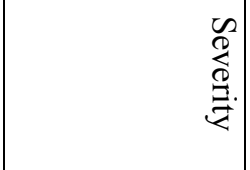 & 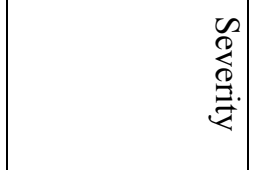 & 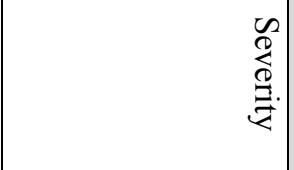 & . & 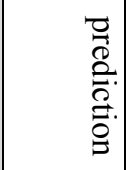 \\
\hline 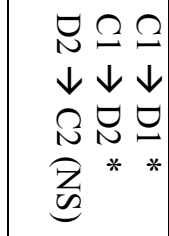 & $\begin{array}{ll}\Xi & \Omega \\
\downarrow & \downarrow \\
\Omega & \ddots \\
z & \Xi \\
\mathscr{E} & \Xi\end{array}$ & 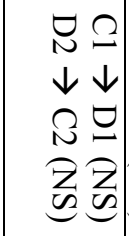 & 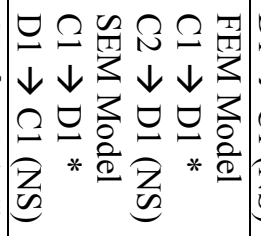 & 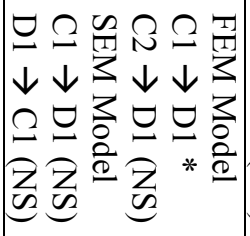 & 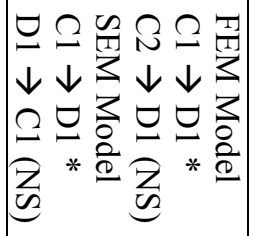 & 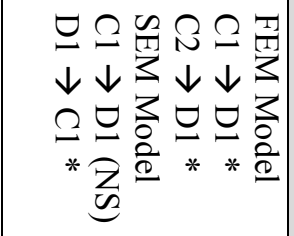 & & 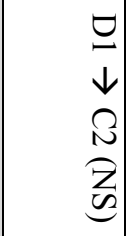 \\
\hline 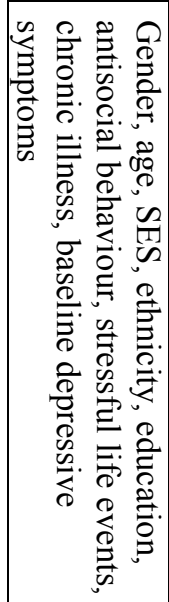 & $\begin{array}{l}0 \\
0 \\
0 \\
0 \\
0 \\
0 \\
0 \\
00 \\
0 \\
0 \\
0 \\
0 \\
0 \\
0 \\
0 \\
0 \\
0 \\
\overline{0} \\
0 \\
0\end{array}$ & 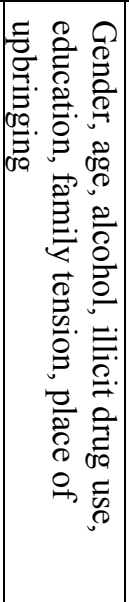 & 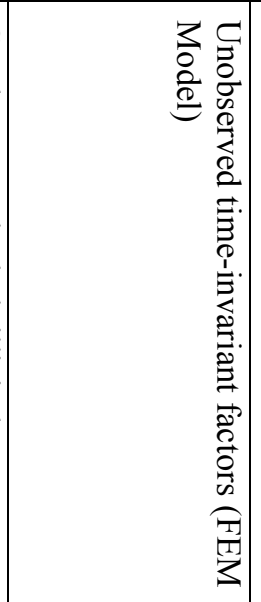 & 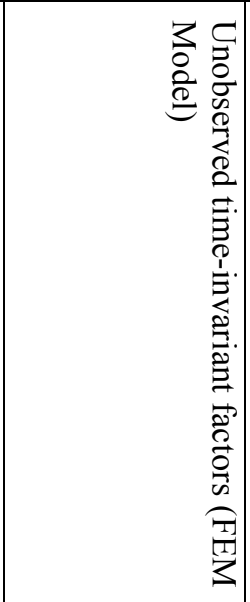 & 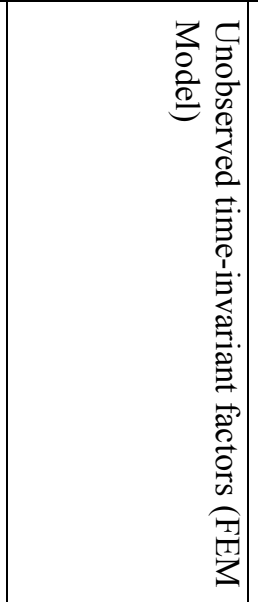 & 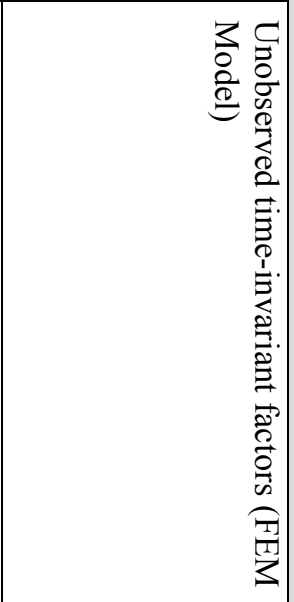 & 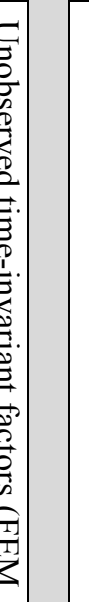 & \\
\hline
\end{tabular}




\begin{tabular}{|c|c|c|c|c|c|c|}
\hline 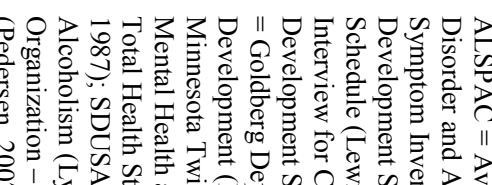 & 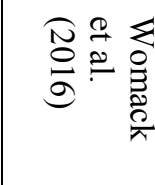 & 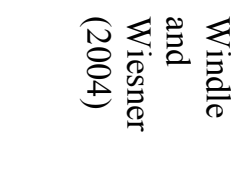 & 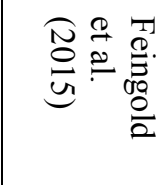 & 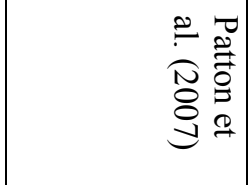 & 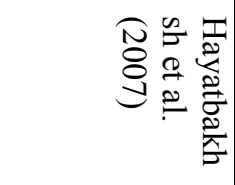 & \\
\hline $\begin{array}{ll}3 & \\
3 \\
0\end{array}$ & 旅 & $\stackrel{\pi}{\Omega}$ & 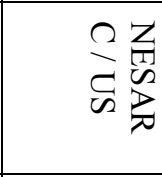 & 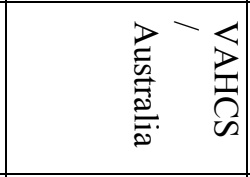 & 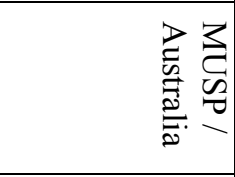 & \\
\hline 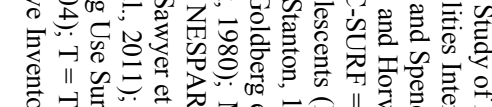 & $\tilde{\Omega}$ & 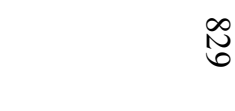 & $\begin{array}{c}w \underset{w}{w} \\
\stackrel{+}{\Delta} \\
\dot{w}\end{array}$ & $\bar{a}$ & 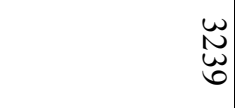 & \\
\hline 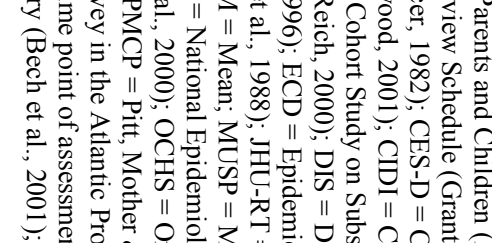 & 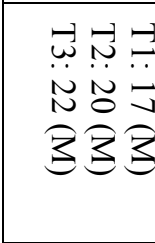 & 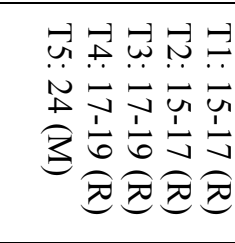 & 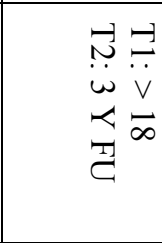 & 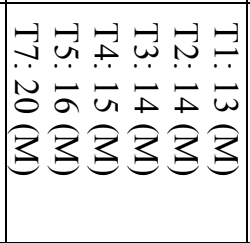 & 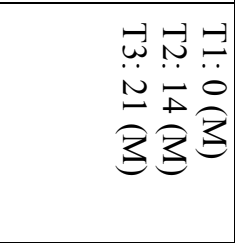 & 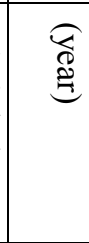 \\
\hline 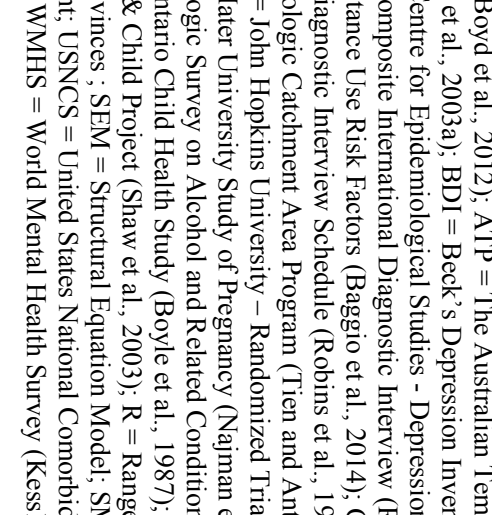 & 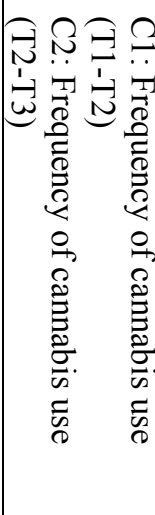 & 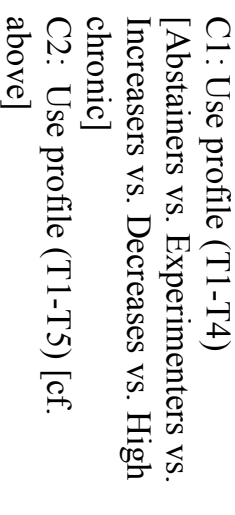 & 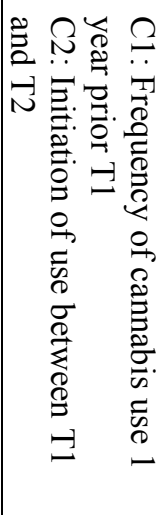 & 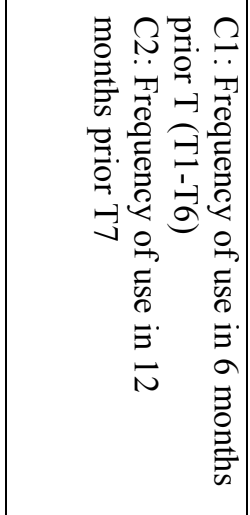 & 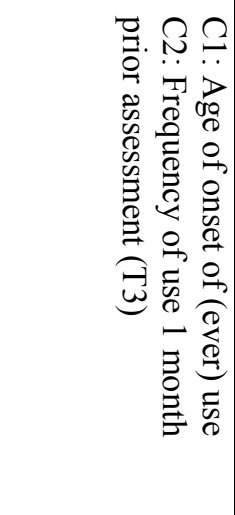 & \\
\hline 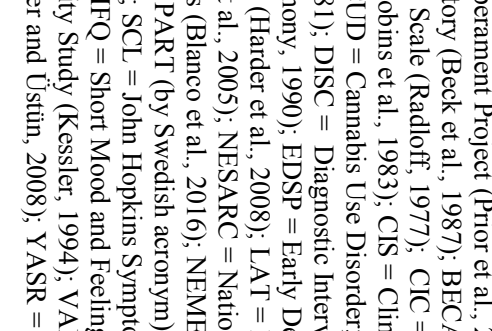 & 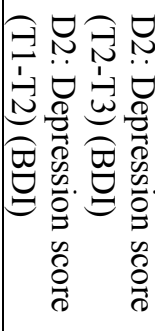 & 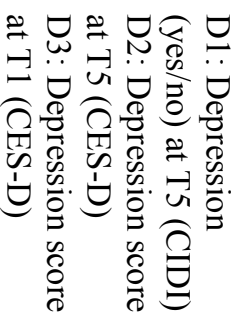 & 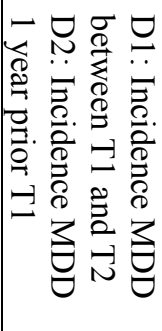 & 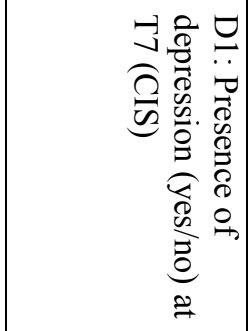 & 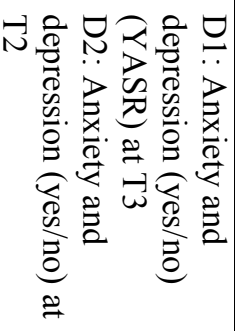 & 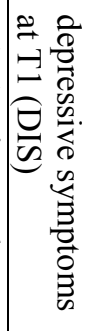 \\
\hline 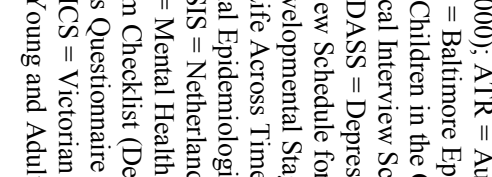 & 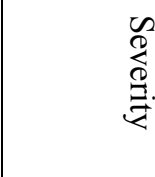 & 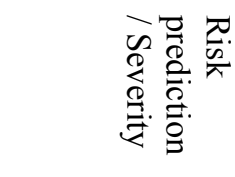 & 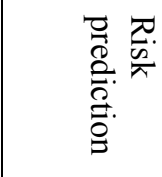 & 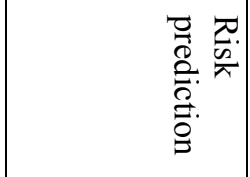 & 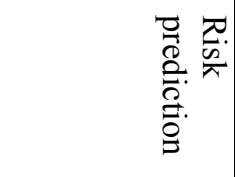 & \\
\hline 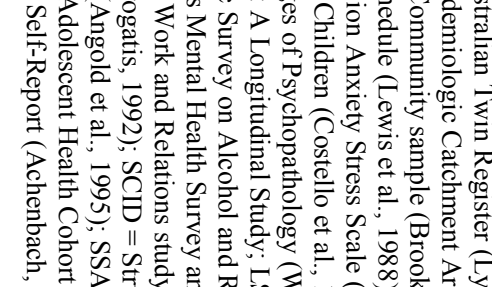 & 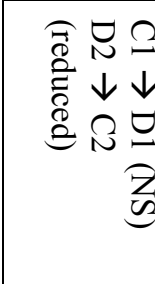 & 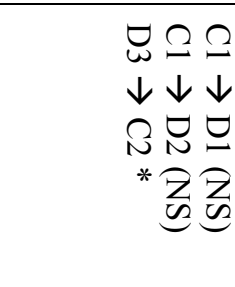 & 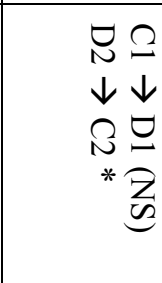 & 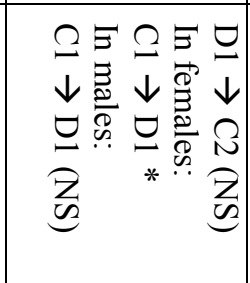 & 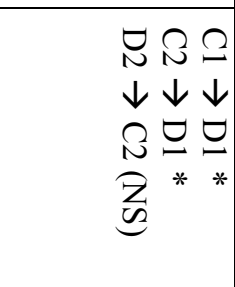 & \\
\hline 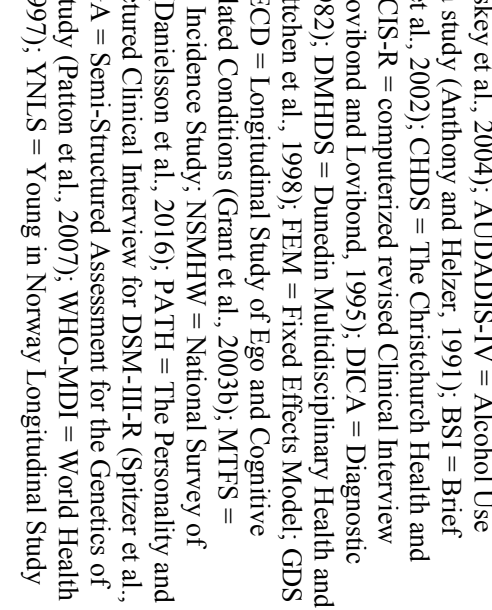 & 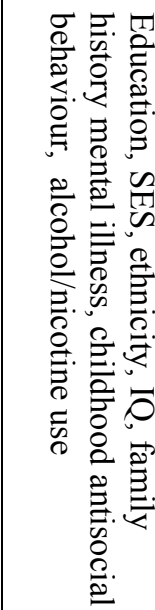 & 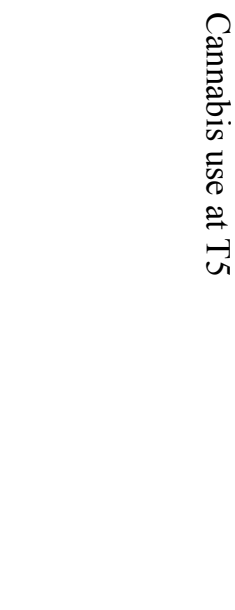 & 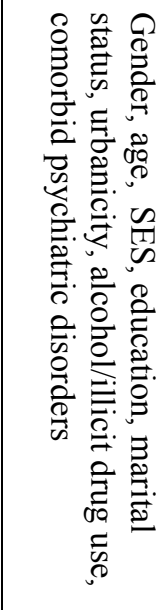 & 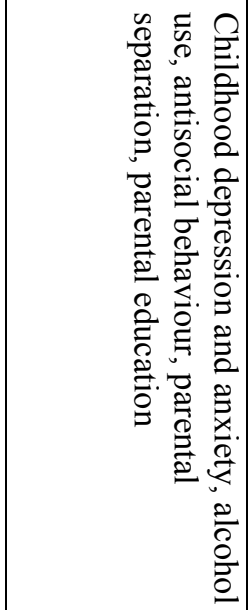 & 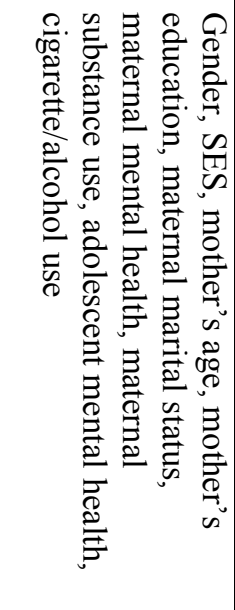 & \\
\hline
\end{tabular}




\section{sAppendix 1. Methods}

\section{Study sample}

The Cambridge Study in Delinquent Development (CSDD), originally designed by Donald J. West and directed since 1982 by David P. Farrington, is a prospective longitudinal study of the development of offending and antisocial behavior in a cohort of 411 boys born mostly in 1953 living in a homogeneous, working class urban area of South London [a review of major findings may be found in several books (West and Farrington, 1977, West and Farrington, 1973, West, 1982, West, 1969, Piquero et al., 2007, Farrington et al., 2013, Farrington et al., 2009) as well as in several summary papers (Farrington et al., 2006a, Farrington, 1995, Farrington and West, 1990)]. The sample comprised a complete population of boys from six primary schools who were aged 8-9 in 1961/62 in a deprived area in South London. Most of the boys (357, 87\%) were White in appearance and of British origin(Farrington et al., 2006b). There were multiple waves (T1- T7) of data collection which included participants being interviewed in their school [at ages 8 (T1), 10 (T2), 14 (T3), in research offices (at ages of 16 (T4) and 18 (T5)] or in their homes (at ages 32 (T6) and 48 (T7)] by social science graduates. Parents were interviewed (about once per year) and questionnaires were completed by the boys' teachers (about once every two years) between ages 8 and 15 to complement information about troublesome/aggressive behavior in school and difficulties at home.

\section{Measures}

Presence of Major Depressive Disorder (MDD)

Lifetime diagnosis of Major Depressive Disorder (MDD) and age of onset of MDD were assessed by a psychiatrist using the Structured Clinical Interview for DSM-IV Axis I Disorders (SCID-I) (First et al., 1998) as part of a psychiatric interview at T7. Subjects were classified as those with or without a lifetime diagnosis (MDD) by age 48 (T7).

Cannabis use

Cannabis use at the ages of 14 (T3) and 18 years (T5) was assessed in terms of frequency of use (number of times used in past 6 months) and ever used (vs. never used) before that time-point of assessment. Cannabis use at ages 32 (T6) and 48 years (T7) was assessed in terms of frequency of use (number of times used in the preceding 5 years) and presence (vs. absence) of use (used more than once in the 5 years preceding the interview).

\section{Covariates}

Covariates included in the simple analysis were chosen based on previous research, reporting a link between depression and:

(1) Alcohol use (Brook et al., 2002, Bovasso, 2014):

a. Self-reported presence (vs. absence) of binge drinking ( at least 13 units of alcohol drunk in one evening in the last month yes/no) was assessed at T5, T6, and T7 and an ordinal variable was computed based on whether binge-drinking was present or not at each of the 3 time-points assessed (score ranging from 0-3).

b. Presence (vs. absence) of a DSM-IV lifetime diagnosis of alcohol use and/or dependence was assessed using the Structured Clinical Interview for DSM-IV Axis I Disorders (SCID-I) (First et al., 1998) as part of the psychiatric interview conducted at age 48 (T7).

(2) Cigarette use (Brook et al., 2002, Georgiades and Boyle, 2007, Pedersen, 2007): Self-reported cigarette use defined as presence of smoking (over 20 cigarettes/ day) was assessed at T5, T6 and T7 and a score (from 0 to 3 ) was computed based on whether smoking was present or not at each of the 3 time-points assessed (scored from 0 - 3).

(3) Other illicit drug use (Brook et al., 2002):

a. Self-reported presence (vs. absence) of illicit drug use (other than cannabis) was assessed at T6 (used $\geq 1$ prior to age 32 ) and was coded as a dichotomized variable.

b. DSM-IV diagnosis of substance use and/or dependence other than cannabis use disorder was assessed using the SCID-I as part of the psychiatric interview at age 48 (T7).

(4) Socioeconomic status (Lorant et al., 2003): Social class assessed at age 10 (T2) was coded as "low" if the family breadwinner had an unskilled manual job. Social class assessed at age 48 (T7) was coded as "low" if a subject had an unskilled manual job or was not working. 
(5) Employment status: Employment status assessed at age 48 was coded as "unemployed" if there was a period of $>5$ months of unemployment in the last 5 years.

(6) Other psychiatric illness: Presence (vs. absence) of a diagnosis of mental illness other than depression or substance abuse/dependence was assessed using the SCID-I as part of a psychiatric interview at age 48 (T7). sTable 2. displays the prevalence rates of other DSM diagnoses in the sample.

(7) Behavioural and emotional problems in childhood (Rey et al., 2002, Windle and Wiesner, 2004, De Graaf et al., 2010) including:

a. Antisocial personality: Antisocial traits were assessed at age 10 (T2) based on teacher, peer, or parent ratings using the antisocial personality scale (AP) (Farrington 1991).

b. Childhood anxiety: Anxiety was assessed at age 10 (T2).

c. Childhood conduct problems: Conduct problems were assessed at age 8 (T1) based on teacher and parent ratings of being "troublesome" and at age 14 (T3) were based on a teacher's rating of being aggressive in school.

\section{Statistical methods}

Data was analysed using R3.1.3 (R Core Team, 2015) comprising three main statistical approaches:

(1) Logistic regression analysis to estimate the effect of cannabis use group on risk of subsequent diagnosis of MDD (presence vs. absence of MDD by age 48). Given the focus on risk of subsequent MDD, we excluded one case where depression was diagnosed prior to the reported use of cannabis [diagnosis received at age 36, admitted to cannabis use at T7 (age 43-48) but not T6 (age 27-32)]. Three cases were classified as cannabis-using subjects prior to the diagnosis of MDD, although we were unable to establish accurately whether onset of cannabis use actually preceded the diagnosis of MDD [ $n=1$ reported cannabis use at T6 (age 27-32) and received diagnosis of MDD at age 30, $n=2$ reported cannabis use at T7 (age 43-48) and received diagnosis of MDD at age 44/43]. To address the potential effects of reverse causation, we carried out further analysis using longitudinal modelling that specifically elaborated on the issue of directionality (cf. fixed-effects analysis below). The cannabis use predictor was coded as a categorical variable that took into account age of first reported use [early-onset user (reported use at age 18 or before) vs. late-onset user (reported use subsequent to age 18)] and frequency of use [high-frequency user $(\geq 450$ times used across T3, T5, T6, T7) vs. low-frequency user $(<450$ times used)]. This cut-off was chosen to generate a "highfrequency" cannabis group based on cannabis use pattern reported by our sample, here defined as greater than twice the third quantile $\left(\mathrm{Q}_{3}\right)$ for number of times used $\left[\mathrm{Q}_{3}=200\right.$ times used in those who used it at least once in their lifetime]. In the regression analyses, these 4 different cannabis use groups were compared to a non-user group as the reference group (no reported use of cannabis at T3, T5, T6 and T7). Multiple regression analysis was carried out including those co-variates that were significantly $(\mathrm{p} \leq 0.05)$ associated with risk of MDD in chi-square tests.

(2) Cox proportional hazard regression analysis was employed to test whether the time until diagnosis of MDD was significantly different between the different cannabis use groups. Person years of follow up (age 0 to age 48) were used as the underlying time-scale. Simple and multiple analyses were carried out, including the same categorical cannabis predictor and covariates as in the logistic regression analysis. The Hazard Ratio (HR) was reported for the cannabis groups, as well as all covariates included in the model (cf. Table 3.).The proportional hazards assumption was checked, revealing that the assumption of proportionality was not violated for any of the variables included.

(3) Fixed-effects logistic regression models were fitted in order to extend the ordinary logistic regression by adjusting for time-invariant, non-observed, fixed factors that vary across individuals, such as family background, genetic influences, personality or pre-existing depressive traits. In order to investigate the potential moderating effect of age of onset and frequency of use, we set up two developmental dependent models, including one that assessed the effect of changes in cannabis frequency [(0) non-user; (1) low frequency user $=<150$ times used at time of assessment (i.e. use less than Q3 per assessment); (2) high-frequency user $=\geq 150$ times used at time of assessment] on risk of development of MDD within the age range of 14-18 years, one within the age range of 18-32 years and one within the age range of 32-48 years. In order to investigate any effect that may have 
occurred in the reverse direction (i.e. reverse causation: development of MDD predisposing to a subsequent increase in cannabis frequency), we ran a second set of fixed-effects models that examined the effect of occurrence of MDD during two distinct developmental periods (diagnosis between 18 to 32 years and diagnosis between 33 to 48 years) as a predictor for subsequent changes in frequency of cannabis use. The simple and multiple regression models were fitted using the $\mathrm{R}$ package lme4 (Bates et al., 2015) for binary (risk of depression) and categorical outcomes (increase in cannabis frequency category). In the multiple model we included other illicit drug use and presence of other mental illness as random-effects.

\section{sAppendix 2. Supplementary Results}

Out of the 411 boys assessed at baseline, complete multi-wave cannabis and depression data (T1-T7) at follow up 48 years later was available for a total number of $\mathrm{N}=285$ (cf. Flow chart, sFigure 1.). Comparing subjects that dropped out throughout follow up $(n=126)$ to completers $(n=285)$ in demographic variables and outcome data revealed that there were no significant differences between the two groups (cf. sTable1).

\section{sAppendix 3. Supplementary Discussion}

Certain limitations should be taken into consideration when interpreting these results. Firstly, the sample included a select group of predominantly white males who grew up in in a working class urban environment in the 1960s and 1970s, for which reason the results may not generalize to females, other ethnicities or social classes. This also limited our ability to investigate any potential moderating effects of gender, as examined in previous studies (Patton et al., 2007, Poulin et al., 2005). Despite the use of longitudinal panel data, this design does not allow us to make definitive conclusions regarding causality since fixed-effects models can neither account for individual unmeasured factors that vary over time nor do they address sufficiently the possibility of reverse causality. However, by exploring a range of potential confounders as well as by testing bi-directional cross-lagged relationships (cannabis on depression and vice versa), the results provide a higher level of evidence in support of cannabis use as a causal risk factor for depression than the majority of the prior studies. Such an analytical design is considered as a quasi-experimental design that is only second best to randomised control trials when identifying causal risk factors (Murray et al., 2009).

Absence of effects of late-onset cannabis use on the risk of subsequent depression may reflect a lack of power to detect such effect. Nevertheless, we found that the effect of changes in cannabis frequency became more pronounced as the age of onset of exposure decreased, suggesting that initiation of cannabis use in later life was associated with a lower risk of developing subsequent MDD. This was further supported by combining the two late-onset groups in order to increase sample power (cf. sTable 7.). Nevertheless, future studies including larger samples should model the effects of cannabis use at different stages across the lifespan in order to derive more precise estimates for age-dependent effects of cannabis use. The inclusion of more frequent follow-up assessments at shorter intervals (e.g. yearly assessments), especially in early neurodevelopmental stages could help explore developmental sensitivities to cannabis use in greater detail. In this context, future studies should also investigate the potential mechanisms of effects of cannabis over the life span. Furthermore, the inclusion of narrower and more numerous follow ups (e.g. yearly assessments), especially in early neurodevelopmental stages, could help to explore questions on developmental sensitivities to cannabis use in more detail. 


\section{sFigure 1. Follow up flow chart}

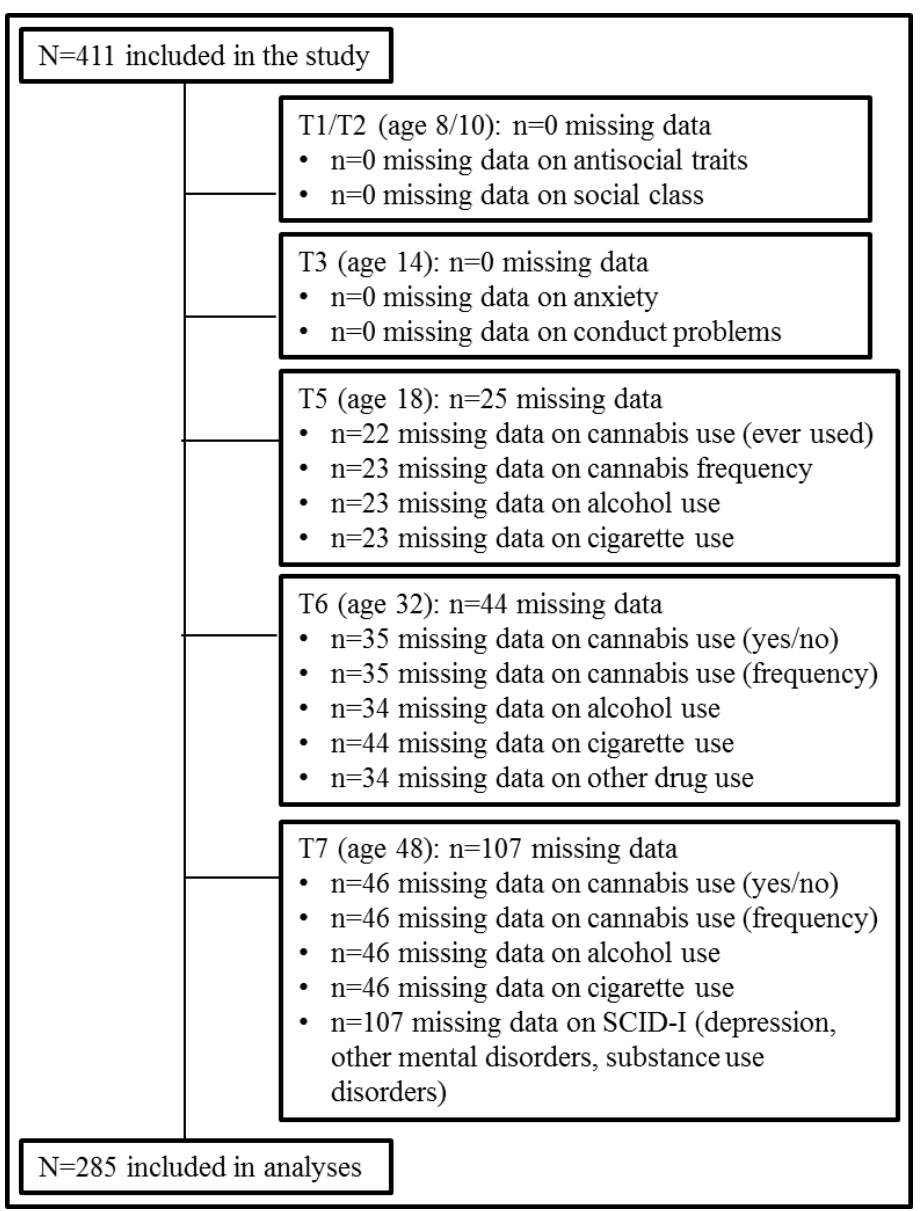

Note. SCID-I = Structured Clinical Interview for DSM-IV Axis I Disorders (First et al., 1998)

sTable 2. Prevalence of diagnosis of other mental illness

\begin{tabular}{lll}
\hline DSM Diagnosis & $\begin{array}{l}\text { Number of subjects } \\
\text { diagnosed }\end{array}$ & Percentage \\
\hline Bipolar & $0 / 285$ & $0 \%$ \\
Schizophrenia & $1 / 285$ & $0.004 \%$ \\
Anxiety/Stress* & $77 / 285$ & $27 \%$ \\
Eating disorder & $2 / 285$ & $0.007 \%$ \\
\hline
\end{tabular}

* Includes panic disorder, obsessive compulsive disorder, post-traumatic stress disorder, anxiety disorder, somatoform disorder, adjustment disorder 
sTable 3. Differences in demographics and outcome in later life and between completers and drop outs

\begin{tabular}{|c|c|c|c|}
\hline & Complete data $\mathbf{n} / \mathbf{n}_{\mathrm{av}}(\%)^{\mathrm{a}}$ & Incomplete data $\mathbf{n} / \mathbf{n}_{\mathrm{av}}(\%)^{\mathrm{a}, \mathrm{b}}$ & $p$ \\
\hline Sample size & $\mathrm{n}=\mathbf{2 8 5}$ & $n=126$ & \\
\hline \multicolumn{4}{|l|}{ Cannabis variables } \\
\hline Cannabis at age 18 (yes) & $82 / 285(29 \%)$ & $27 / 105(28 \%)$ & 0.86 \\
\hline Cannabis at age 32 (yes) & $50 / 285(17.5 \%)$ & $19 / 91(21 \%)$ & 0.47 \\
\hline Cannabis at age 48 (yes) & $44 / 285(15 \%)$ & $11 / 80(14 \%)$ & 0.71 \\
\hline \multicolumn{4}{|l|}{ Mental health outcome (DSM diagnosis) } \\
\hline Lifetime diagnosis depression (yes) & $58 / 285(20 \%)$ & $2 / 19(11 \%)$ & 0.30 \\
\hline Lifetime diagnosis anxiety disorder (yes) & $73 / 285(26 \%)$ & $4 / 19(21 \%)$ & 0.19 \\
\hline Other substance use disorder (yes) & $29 / 285(10 \%)$ & $2 / 19(11 \%)$ & 0.96 \\
\hline Alcohol use disorder (yes) & $56 / 285(20 \%)$ & $3 / 19(16 \%)$ & 0.68 \\
\hline Any mental health diagnosis (yes) ${ }^{\mathrm{b}}$ & $171 / 285(40 \%)$ & $5 / 19(21 \%)$ & 0.24 \\
\hline \multicolumn{4}{|l|}{ Early life variables } \\
\hline Alcohol use at 18 (yes) & $57 / 285(20 \%)$ & $24 / 103(23 \%)$ & 0.48 \\
\hline Cigarette use at 18 (yes) & $78 / 284(28 \%)$ & $26 / 104(25 \%)$ & 0.63 \\
\hline Antisocial Personality at age 10 (yes) & $65 / 285(23 \%)$ & $33 / 126(26 \%)$ & 0.46 \\
\hline Low social class at age 10 (yes) & $50 / 285(18 \%)$ & $29 / 126(23 \%)$ & 0.19 \\
\hline Anxiety at age 14 (yes) & $25 / 285(9 \%)$ & $13 / 126(10 \%)$ & 0.62 \\
\hline Conduct problems at age 14 (yes) & $99 / 285(35 \%)$ & $35 / 126(28 \%)$ & 0.17 \\
\hline \multicolumn{4}{|l|}{ Late life variables } \\
\hline Other illicit drug use at age 32 (yes) & $25 / 285(9 \%)$ & $11 / 92(12 \%)$ & 0.37 \\
\hline Cigarette use at 48 (yes) & $71 / 285(25 \%)$ & $20 / 80(25 \%)$ & 0.99 \\
\hline Alcohol use at 48 (yes) & $59 / 285(21 \%)$ & $19 / 80(24 \%)$ & 0.56 \\
\hline
\end{tabular}

Note. $p=\mathrm{p}$-value for chi-square test

a Prevalence reported for $n$ (number of subjects scoring "yes" for the variable of interest) out of $\mathrm{n}_{\mathrm{av}}$ (total number of subjects for which data was available)

${ }^{\mathrm{b}}$ Subjects with incomplete data include those who dropped out ( $\mathrm{n}=107$ that did not complete the SCID-I interview) and those with missing data in other variables $(n=19)$

${ }^{\mathrm{c}}$ Including bipolar, schizophrenia, depression, panic disorder, obsessive compulsive disorder, post-traumatic stress disorder, anxiety disorder, somatoform disorder, adjustment disorder, any substance use disorder

sTable 4. Childhood and life factors associated with risk of MDD by age $48(\mathrm{~N}=284)^{*}$

\begin{tabular}{lcc}
\hline \hline & $\chi 2$ & $p$ \\
\hline Cannabis use (ever/SR) & 9.93 & $\mathbf{0 . 0 0 2}$ \\
Cigarette use (cum/SR) & 0.24 \\
Alcohol use (cum/SR) & 4.18 & 1.00 \\
Alcohol (DSM Diagnosis) & 0.03 & 0.08 \\
Presence other illicit substance use (SR) & 3.14 & $\mathbf{0 . 0 0 9}$ \\
Presence substance use disorder (DSM) & 6.79 & 0.29 \\
Other mental illness (DSM Diagnosis) & 1.14 & $\mathbf{0 . 0 0 8}$ \\
Anxiety at age 14 (yes) & 6.85 & 0.61 \\
Antisocial at age 10 (yes) & 0.26 & 0.47 \\
Conduct problems at age 14 (yes) & 0.52 & 0.25 \\
Low social class at age 10 (yes) & 1.31 & 0.65 \\
Low social class at age 48 (yes) & 0.20 & 0.29 \\
Employment status at age 48 (unemployed) & 1.13 & $\mathbf{0 . 0 0 1}$ \\
\hline
\end{tabular}

Note. DSM = Diagnosis based on Structured Clinical Interview for DSM-IV Axis I Disorders (First et al., 1998); SR = Self-reported.

${ }^{1}$ missing data for $\mathrm{n}=2$

* $\mathrm{n}=1$ cases excluded since MDD was diagnosed prior to cannabis use 
sTable 5. Anxiety and risk of subsequent MDD: Logistic regression analysis*

\begin{tabular}{lccc}
\hline \hline Multiple logistic regression $(\mathrm{N}=284)$ & OR & $\mathbf{9 5 \%}$ CI & $\boldsymbol{p}$ \\
\hline Cannabis late onset - low frequency & 0.68 & $0.10-2.65$ & 0.63 \\
Cannabis late onset - high frequency & 2.23 & $0.25-15.10$ & 0.42 \\
Cannabis early onset - low frequency & 2.41 & $1.22-4.76$ & $\mathbf{0 . 0 1}$ \\
Cannabis early onset - high frequency & 8.83 & $1.29-70.97$ & $\mathbf{0 . 0 3}$ \\
Other mental illness & 2.18 & $1.15-4.14$ & $\mathbf{0 . 0 2}$ \\
Other illicit drug use & 1.10 & $0.28-3.76$ & 0.89 \\
Employment status (unemployed) & 2.34 & $1.18-4.58$ & $\mathbf{0 . 0 1}$ \\
Anxiety at age 14 & 1.01 & $0.32-2.81$ & 0.99 \\
\hline
\end{tabular}

Note. Early onset $=$ Cannabis use at age 18 or before; High frequency $=\geq 450$ cumulative number of times used across time points (age $18,32,48)$

$*_{n}=1$ cases excluded since MDD was diagnosed prior to cannabis use. Reference group = never cannabis users

sTable 6. Anxiety/stress disorder and risk of MDD: Logistic regression analysis ${ }^{\mathrm{a}}$

\begin{tabular}{lccc}
\hline \hline Multiple logistic regression $(\mathrm{N}=284)$ & OR & $\mathbf{9 5 \%}$ CI & $\boldsymbol{p}$ \\
\hline Cannabis late onset - low frequency & 0.67 & $0.10-2.62$ & 0.62 \\
Cannabis late onset - high frequency & 2.51 & $0.28-17.42$ & 0.36 \\
Cannabis early onset - low frequency & 2.43 & $1.22-4.80$ & $\mathbf{0 . 0 1}$ \\
Cannabis early onset - high frequency & 8.78 & $1.27-71.62$ & $\mathbf{0 . 0 3}$ \\
Anxiety/Stress & 2.41 & $1.26-4.60$ & $\mathbf{0 . 0 1}$ \\
Other illicit drug use & 1.11 & $0.28-3.87$ & 0.87 \\
Employment status (unemployed) & 2.32 & $1.18-4.52$ & $\mathbf{0 . 0 1}$ \\
\hline
\end{tabular}

Note. Early onset $=$ Cannabis use at age 18 or before; High frequency $=\geq 450$ cumulative number of times used across time points (age 18, 32, 48)

${ }^{a} \mathrm{n}=1$ cases excluded since MDD was diagnosed prior to cannabis use. Reference group = never cannabis users

${ }^{\mathrm{b}}$ Includes panic disorder, obsessive compulsive disorder, post-traumatic stress disorder, anxiety disorder, somatoform disorder, adjustment disorder

sTable 7. Sensitivity analysis: Cannabis profiles and risk of subsequent MDD (Logistic regression analyses)*

\begin{tabular}{lccc}
\hline \hline Simple logistic regression $(\mathrm{N}=284)$ & OR & $\mathbf{9 5 \%}$ CI & $\boldsymbol{p}$ \\
\hline Cannabis late onset & 1.15 & $0.32-3.34$ & 0.81 \\
Cannabis early onset - low frequency & 2.67 & $1.39-5.12$ & $\mathbf{0 . 0 0 3}$ \\
Cannabis early onset - high frequency & 10.07 & $2.33-51.61$ & $\mathbf{0 . 0 0 2}$
\end{tabular}

Note. Reference group = never cannabis users; Early onset = Cannabis use at age 18 or before; High frequency $=\geq 450$ cumulative number of times used across time points (ages 18, 32, 48)

$*_{n}=1$ cases excluded since MDD was diagnosed prior to cannabis use 


\section{sReferences}

Achenbach TM (1997). Manual for the young adult self-report and young adult behavior checklist, University of Vermont, Department of Psychiatry.

Angold A, Costello EJ, Messer SC, Pickles A, Winder F \& Silver D (1995). Development of a short questionnaire for use in epidemiological studies of depression in children and adolescents. International Journal of Methods in Psychiatric Research, 237-249.

Anstey KJ, Christensen H, Butterworth P, Easteal S, Mackinnon A, Jacomb T, Maxwell K, Rodgers B, Windsor T \& Cherbuin N (2011). Cohort Profile: The PATH through life project. International journal of epidemiology, dyr025.

Anthony J \& Helzer J (1991). Psychiatric Disorders in America: the Epidemiological Catchment Area study.

Arseneault L, Cannon M, Poulton R, Murray R, Caspi A \& Moffitt TE (2002). Cannabis use in adolescence and risk for adult psychosis: longitudinal prospective study. British Medical Journal 325, 1212-1213.

Baggio S, N'goran AA, Deline S, Studer J, Dupuis M, Henchoz Y, Mohler-Kuo M, Daeppen J-B \& Gmel G (2014). Patterns of cannabis use and prospective associations with health issues among young males. Addiction 109, 937-945.

Bates D, Maechler M, Bolker B, Walker S, Christensen RHB, Singmann H, Dai B, Eigen C \& Rcpp L (2015). Package 'lme4'.

Bech P, Rasmussen NA, Olsen LR, Noerholm V \& Abildgaard W (2001). The sensitivity and specificity of the Major Depression Inventory, using the Present State Examination as the index of diagnostic validity. Journal of affective disorders 66, 159-164.

Beck AT, Steer R \& Brown G (1987). Beck Depression Inventory Manual. San Antonio, TX: The Psychological Corporation. Archives of General Psychiatry 4, 561-571.

Blanco C, Hasin DS, Wall MM \& Et Al. (2016). Cannabis use and risk of psychiatric disorders: Prospective evidence from a us national longitudinal study. JAMA Psychiatry.

Block J \& Block J (1980). The California child Q-set. Consulting Psychologists.

Block JH, Gjerde PF \& Block JH (1991). Personality antecedents of depressive tendencies in 18-year-olds: a prospective study. Journal of Personality and Social Psychology 60, 726.

Bovasso GB (2014). Cannabis abuse as a risk factor for depressive symptoms. American Journal of Psychiatry.

Boyd A, Golding J, Macleod J, Lawlor DA, Fraser A, Henderson J, Molloy L, Ness A, Ring S \& Smith GD (2012). Cohort profile: the 'children of the 90s' - the index offspring of the Avon Longitudinal Study of Parents and Children. International journal of epidemiology, dys064.

Boyle MH, Offord DR, Hofmann HG, Catlin GP, Byles JA, Cadman DT, Crawford JW, Links PS, Rae-Grant NI \& Szatmari P (1987). Ontario child health study: I. Methodology. Archives of General Psychiatry 44, 826831.

Brook DW, Brook JS, Zhang C, Cohen P \& Whiteman M (2002). Drug use and the risk of major depressive disorder, alcohol dependence, and substance use disorders. Arch Gen Psychiatry 59, 1039-1044. 
Chen C-Y, Wagner FA \& Anthony JC (2002). Marijuana use and the risk of Major Depressive Episode. Social psychiatry and psychiatric epidemiology 37, 199206.

Costello A, Edelbrock C, Kalas R, Kessler M \& Klaric SA (1982). Diagnostic interview schedule for children (DISC). Bethesda, MD: National Institute of Mental Health.

Danielsson A-K, Lundin A, Agardh E, Allebeck P \& Forsell Y (2016). Cannabis use, depression and anxiety: A 3-year prospective population-based study. Journal of Affective Disorders 193, 103-108.

De Graaf R, Radovanovic M, Van Laar M, Fairman B, Degenhardt L, AguilarGaxiola S, Bruffaerts R, De Girolamo G, Fayyad J \& Gureje O (2010). Early cannabis use and estimated risk of later onset of depression spells: Epidemiologic evidence from the population-based World Health Organization World Mental Health Survey Initiative. American journal of epidemiology, kwq096.

Degoratis L \& Spencer P (1982). The brief symptom inventory (BSI): administration, scoring and procedures manual-I. Baltimore, MD: Clinical Psychometric Research.

Derogatis LR (1992). SCL-90-R: Administration, Scoring of Procedures Manual-II for the R (evised) Version and Other Instruments of the Psychopathology Rating Scale Series, Clinical Psychometric Research Incorporated.

Farrington D, Coid JW, Jolliffe D, Soteriou N, Turner RE \& West DJ (2006a). Criminal careers up to age 50 and life success up to age 48: New findings from the Cambridge Study in Delinquent Development, Home Office Research, Development and Statistics Directorate.

Farrington D, Piquero AR \& Jennings WG (2013). Offending from childhood to late middle age: Recent results from the Cambridge study in delinquent development, Springer Science \& Business Media.

Farrington DP (1995). The development of offending and antisocial behaviour from childhood: Key findings from the Cambridge Study in Delinquent Development. Journal of Child Psychology and Psychiatry 36, 929-964.

Farrington DP, Coid JW, Harnett L, Jolliffe D, Soteriou N, Turner R \& West DJ (2006b). Criminal careers up to age 50 and life success up to age 48: New findings from the Cambridge Study in Delinquent Development, London, Home Office Research, Development and Statistics Directorate London.

Farrington DP, Coid JW \& West DJ (2009). The development of offending from age 8 to age 50: Recent results from the Cambridge Study in Delinquent Development. Monatsschrift fur Kriminologie und Strafrechtsreform 92, 160173.

Farrington DP \& West DJ (1990). The Cambridge study in delinquent development: A long-term follow-up of 411 London males, Springer.

Feingold D, Weiser M, Rehm J \& Lev-Ran S (2015). The association between cannabis use and mood disorders: A longitudinal study. J Affect Disord 172, 211-218.

Fergusson DM \& Horwood JL (2001). The Christchurch Health and Development Study: review of findings on child and adolescent mental health. Australian and New Zealand Journal of Psychiatry 35, 287-296.

First MB, Spitzer RL, Gibbon M \& Williams JB (1998). Structured Clinical Interview for DSM-IV Axis I Disorders: Patient Edition (February 1996 
Final), SCID-I/P, New York, Biometrics Research Department, New York State Psychiatric Institute.

Gage SH, Hickman M, Heron J, Munafò MR, Lewis G, Macleod J \& Zammit S (2015). Associations of Cannabis and Cigarette Use with Depression and Anxiety at Age 18: Findings from the Avon Longitudinal Study of Parents and Children. PloS one $\mathbf{1 0 .}$

Georgiades K \& Boyle MH (2007). Adolescent tobacco and cannabis use: young adult outcomes from the Ontario Child Health Study. Journal of Child Psychology and Psychiatry 48, 724-731.

Goldberg D, Bridges K, Duncan-Jones P \& Grayson D (1988). Detecting anxiety and depression in general medical settings. British Medical Journal 297, 897899.

Grant BF, Dawson DA, Stinson FS, Chou PS, Kay W \& Pickering R (2003a). The Alcohol Use Disorder and Associated Disabilities Interview Schedule-IV (AUDADIS-IV): reliability of alcohol consumption, tobacco use, family history of depression and psychiatric diagnostic modules in a general population sample. Drug and alcohol dependence 71, 7-16.

Grant BF, Moore T, Shepard J \& Kaplan K (2003b). Source and accuracy statement: wave 1 national epidemiologic survey on alcohol and related conditions (NESARC). National Institute on Alcohol Abuse and Alcoholism 52.

Harder VS, Stuart EA \& Anthony JC (2008). Adolescent cannabis problems and young adult depression: male-female stratified propensity score analyses. American journal of epidemiology 168, 592-601.

Hayatbakhsh MR, Najman JM, Jamrozik K, Mamun AA, Alati R \& Bor W (2007). Cannabis and anxiety and depression in young adults: a large prospective study. J Am Acad Child Adolesc Psychiatry 46, 408-417.

Horwood LJ, Fergusson DM, Coffey C, Patton GC, Tait R, Smart D, Letcher P, Silins E \& Hutchinson DM (2012). Cannabis and depression: an integrative data analysis of four Australasian cohorts. Drug Alcohol Depend 126, 369378.

Kessler RC (1994). The national comorbidity survey of the United States. International Review of Psychiatry 6, 365-376.

Kessler RC \& Üstün TB (2008). The WHO World Mental Health Surveys: global perspectives on the epidemiology of mental disorders, Cambridge University Press New York.

King SM, Iacono WG \& Mcgue M (2004). Childhood externalizing and internalizing psychopathology in the prediction of early substance use. Addiction 99, 1548-1559.

Lewis G, Pelosi AJ, Araya R \& Dunn G (1992). Measuring psychiatric disorder in the community: a standardized assessment for use by lay interviewers. Psychological medicine 22, 465-486.

Lewis G, Pelosi AJ, Glover E, Wilkinson G, Stansfeld SA, Williams P \& Shepherd M (1988). The development of a computerized assessment for minor psychiatric disorder. Psychological medicine 18, 737-745.

Lorant V, Deliège D, Eaton W, Robert A, Philippot P \& Ansseau M (2003). Socioeconomic inequalities in depression: a meta-analysis. American journal of epidemiology 157, 98-112.

Lovibond \& Lovibond (1995). Manual for the depression anxiety stress scale. Psychology Foundation Sydney. 
Lynskey MT, Glowinski AL, Todorov AA, Bucholz KK, Madden PaF, Nelson EC, Statham DJ, Martin NG \& Heath AC (2004). Major Depressive Disorder, Suicidal Ideation, and Suicide Attempt inTwins Discordant for Cannabis Dependence and Early-Onset Cannabis Use. Arch Gen Psychiatry 61, 1026-1032.

Marmorstein NR \& Iacono WG (2011). Explaining associations between cannabis use disorders in adolescence and later major depression: A test of the psychosocial failure model. Addictive Behaviors 36, 773-776.

Murray J, Farrington DP \& Eisner MP (2009). Drawing conclusions about causes from systematic reviews of risk factors: The Cambridge Quality Checklists. Journal of Experimental Criminology 5, 1-23.

Najman JM, Bor W, O'callaghan M, Williams GM, Aird R \& Shuttlewood G (2005). Cohort profile: the Mater-University of Queensland study of pregnancy (MUSP). International journal of epidemiology 34, 992-997.

Patton GC, Coffey C, Lynskey MT, Reid S, Hemphill S, Carlin JB \& Hall W (2007). Trajectories of adolescent alcohol and cannabis use into young adulthood. Addiction 102, 607-615.

Pedersen W (2007). Childbirth, abortion and subsequent substance use in young women: a population-based longitudinal study. Addiction 102, 1971-1978.

Piquero AR, Farrington DP \& Blumstein A (2007). Key issues in criminal career research: New analyses of the Cambridge study in delinquent development, Cambridge University Press.

Poulin C, Hand D, Boudreau B \& Santor D (2005). Gender differences in the association between substance use and elevated depressive symptoms in a general adolescent population. Addiction 100, 525-535.

Prior MR, Sanson A, Smart D \& Oberklaid F (2000). Pathways from infancy to adolescence: Australian Temperament Project 1983-2000, Australian Institute of Family Studies Melbourne.

R Core Team. (2015). R: A Language and Environment for Statistical Computing [Online]. Vienna, Austria. Available: https://cran.rproject.org/doc/manuals/fullrefman.pdf [Accessed 09/09 2015].

Radloff LS (1977). The CES-D scale a self-report depression scale for research in the general population. Applied psychological measurement 1, 385-401.

Reich W (2000). Diagnostic interview for children and adolescents (DICA). Journal of the American Academy of Child \& Adolescent Psychiatry 39, 59-66.

Repetto PB, Zimmerman MA \& Caldwell CH (2008). A Longitudinal Study of Depressive Symptoms and Marijuana Use in a Sample of Inner-City African Americans. J Res Adolesc 18, 421-447.

Rey JM, Sawyer MG, Raphael B, Patton GC \& Lynskey M (2002). Mental health of teenagers who use cannabis. The British Journal of Psychiatry 180, 216221.

Robins LN, Helzer JE, Croughan J \& Ratcliff KS (1981). National Institute of Mental Health diagnostic interview schedule: its history, characteristics, and validity. Archives of General Psychiatry 38, 381-389.

Robins LN, Wing JK \& Helzer JE (1983). Composite International Diagnostic Interview (CIDI) World Health Organization. Geneva, Switzerland.

Sawyer M, Arney F, Baghurst P, Clark J, Graetz B, Kosky R, Nurcombe B, Patton G, Prior M \& Raphael B (2000). The mental health of young people in Australia. Canberra: Mental Health and Special Programs Branch, Commonwealth Department of Health and Aged Care. 
Shaw DS, Gilliom M, Ingoldsby EM \& Nagin DS (2003). Trajectories leading to school-age conduct problems. Developmental psychology 39, 189.

Silva PA \& Stanton WR (1996). From child to adult: The Dunedin multidisciplinary health and development study, Oxford University Press.

Spitzer R, Williams J, Gibbons M \& First M (1987). Structured clinical interview for DSM-III-R (SCID), biometrics research division. New York: New York State Psychiatric Institute.

Tien AY \& Anthony JC (1990). Epidemiological analysis of alcohol and drug use as risk factors for psychotic experiences. The Journal of nervous and mental disease 178, 473\&hyhen.

Troisi A, Pasini A, Saracco M \& Spalletta G (1998). Psychiatric symptoms in male cannabis users not using other illicit drugs. Addiction 93, 487-492.

Van Laar M, Van Dorsselaer S, Monshouwer K \& De Graaf R (2007). Does cannabis use predict the first incidence of mood and anxiety disorders in the adult population? Addiction 102, 1251-1260.

West DJ (1969). Present Conduct and Future Delinquency, London, Heinemann.

West DJ (1982). Delinquency, its roots, careers, and prospects, Harvard University Press.

West DJ \& Farrington DP (1973). Who becomes delinquent? Second report of the Cambridge Study in Delinquent Development, London, Heinemann.

West DJ \& Farrington DP (1977). The delinquent way of life, London, Heinemann.

Windle M \& Wiesner M (2004). Trajectories of marijuana use from adolescence to young adulthood: Predictors and outcomes. Development and psychopathology 16, 1007-1027.

Wittchen H-U, Fröhlich C, Behrendt S, Günther A, Rehm J, Zimmermann P, Lieb R \& Perkonigg A (2007). Cannabis use and cannabis use disorders and their relationship to mental disorders: a 10-year prospective-longitudinal community study in adolescents. Drug Alcohol Depend 88, S60-S70.

Wittchen H-U, Nelson CB \& Lachner G (1998). Prevalence of mental disorders and psychosocial impairments in adolescents and young adults. Psychological medicine 28, 109-126.

Womack SR, Shaw DS, Weaver CM \& Forbes EE (2016). Bidirectional associations between cannabis use and depressive symptoms from adolescence through early adulthood among at-risk young men. J Stud Alcohol Drugs 77, 287-297. 